ISD97, a Computer Program to Analyze Data

From a Series of In Situ Measurements

on a Grid and Identify Potential Localized Are of Elevated Activity

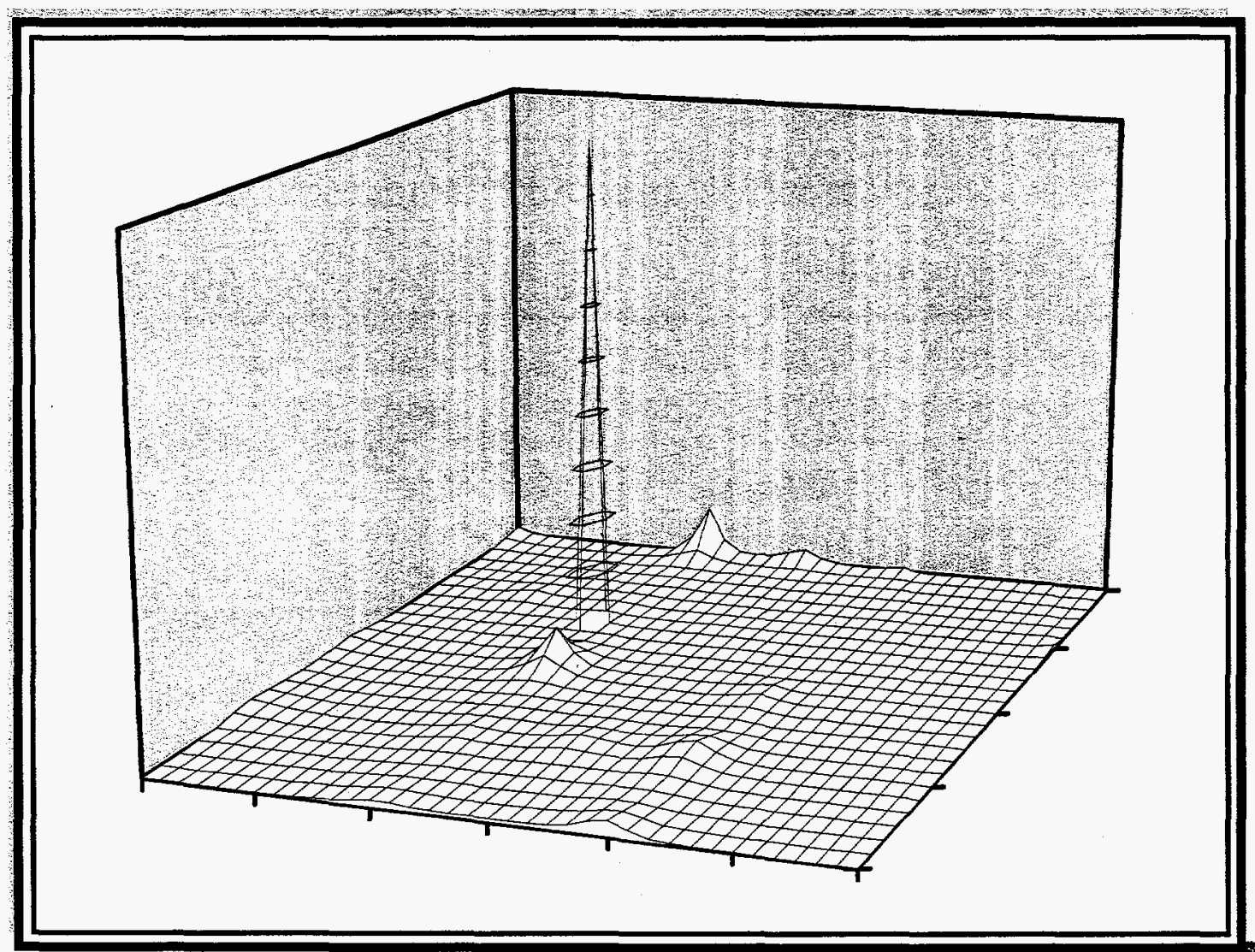

Marcel Reginatto, Peter Shebell and Kevin M. Miller 
EML-590

\title{
ISD97, A COMPUTER PROGRAM TO ANALYZE DATA FROM A SERIES OF IN SITU MEASUREMENTS ON A GRID AND IDENTIFY POTENTIAL LOCALIZED AREAS OF ELEVATED ACTIVITY
}

\author{
Marcel Reginatto, Peter Shebell and Kevin M. Miller
}

\author{
Environmental Measurements Laboratory \\ U.S. Department of Energy \\ 201 Varick Street, 5th Floor \\ New York, NY 10014-4811
}

October 1997

\section{DISCLAIMER}

"This report was prepared as an account of work sponsored by an agency of the United States Government. Neither the United States Government nor any agency thereof, nor any of their employees, makes any warranty, express or implied, or assumes any legal liability or responsibility for the accuracy, completeness, or usefulness of any information, apparatus, product, or process disclosed, or represents that its use would not infringe privately owned rights. Reference herein to any specific commercial product, process, or service by trade name, trademark, manufacturer, or otherwise, does not necessarily constitute or imply its endorsement, recommendation, or favoring by the United States Government or any agency thereof. The views and opinions of authors expressed herein do not necessarily state or reflect those of the United States Government or any agency thereof."

This report has been reproduced directly from the best available copy.

Available to DOE and DOE Contractors from the Office of Scientific and Technical Information, P. O. Box 62, Oak Ridge, TN 37831; prices available from (423) 576-8401.

Available to the public from the U.S. Department of Commerce, Technology Administration, National Technical Information Service, 5285 Port Royal Road, Springfield, Virginia 22161, (703) 487-4650. 


\section{DISCLAIMER}

Portions of this document may be illegible electronic image products. Images are produced from the best available original document. 


\section{A bstract}

A computer program, ISD97, was developed to analyze data from a series of in situ measurements on a grid and identify potential localized areas of elevated activity. The ISD97 code operates using a two-step process. A deconvolution of the data is carried out using the maximum entropy method, and a map of activity on the ground that fits the data within experimental error is generated. This maximum entropy map is then analyzed to determine the locations and magnitudes of potential areas of elevated activity that are consistent with the data. New deconvolutions are then carried out for each potential area of elevated activity identified by the code. Properties of the algorithm are demonstrated using data from actual field measurements. 


\section{T able of Contents}

Abstract $\ldots \ldots \ldots \ldots \ldots \ldots \ldots \ldots \ldots \ldots \ldots \ldots \ldots \ldots \ldots \ldots \ldots \ldots \ldots \ldots \ldots, \quad i$

Introduction $\ldots \ldots \ldots \ldots \ldots \ldots \ldots \ldots \ldots \ldots \ldots \ldots \ldots \ldots \ldots \ldots \ldots \ldots, 1$

Analysis of in situ Measurements on a Grid $\ldots \ldots \ldots \ldots \ldots \ldots \ldots \ldots \ldots$

Deconvolution of in situ Measurements on a Grid ................. 3

The Code ISD97 ...................................... 5

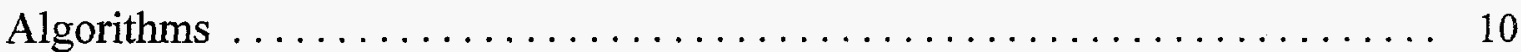

The Subroutine MAXENT $\ldots \ldots \ldots \ldots \ldots \ldots \ldots \ldots \ldots \ldots \ldots \ldots \ldots$

The Subroutine LMBDAS $\ldots \ldots \ldots \ldots \ldots \ldots \ldots \ldots \ldots \ldots \ldots \ldots \ldots \ldots \ldots \ldots, 12$

The Subroutine FRPRMN $\ldots \ldots \ldots \ldots \ldots \ldots \ldots \ldots \ldots \ldots \ldots \ldots \ldots$

The Subroutine PEAKZELS $\ldots \ldots \ldots \ldots \ldots \ldots \ldots \ldots \ldots \ldots \ldots \ldots$

The Subroutine FINDHS $\ldots \ldots \ldots \ldots \ldots \ldots \ldots \ldots \ldots \ldots \ldots \ldots \ldots$

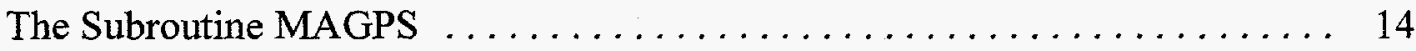

The Subroutine MAGPSNN $\ldots \ldots \ldots \ldots \ldots \ldots \ldots \ldots \ldots \ldots \ldots \ldots \ldots$

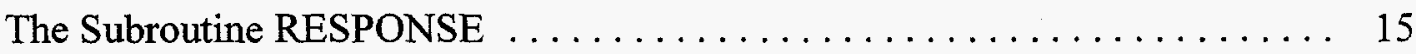

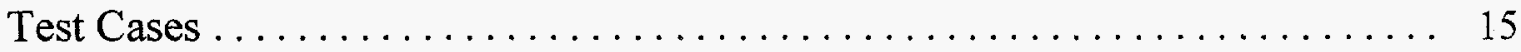

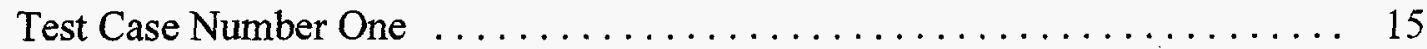

Test Case Number Two ............................. 17

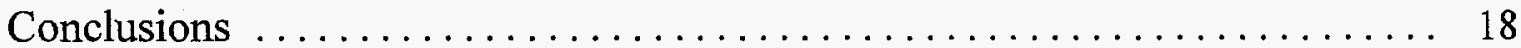

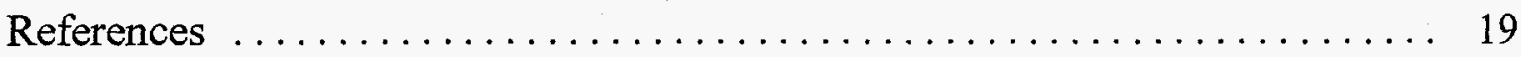

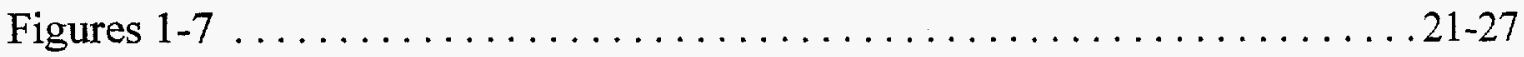

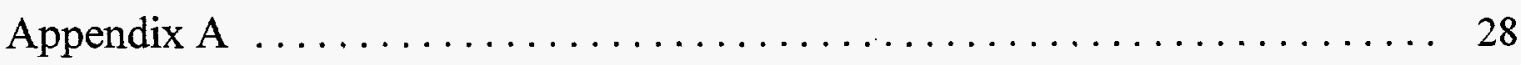

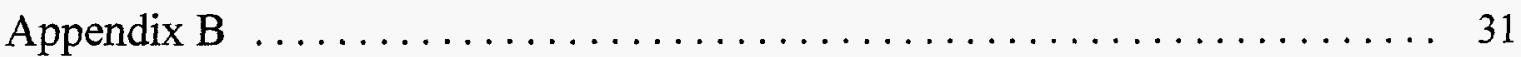




\section{NTRODUCTION}

An important requirement in surveying for residual radioactivity is the detection of localized areas of elevated contamination, sometimes referred to as hot spots. We have developed a computer program that analyzes data from a series of in situ gamma-ray spectrometry measurements on a grid and searches for hot spots that might be "hidden" in the data. The program is designed to be used as a tool when evaluating compliance with regulations that set limits on the size and magnitude of hot spots. Since the program uses in situ measurements, the data are nuclide specific and reproducible. Therefore, our method is useful where standard techniques, such as scanning surveys, do not have the necessary sensitivity.

\section{Analysis of in situ Measurements on a Grid}

In the in situ gamma-ray spectrometry technique, a detector typically positioned $1 \mathrm{~m}$ above the ground facing downwards is used to measure the spectral distribution of photon fluence due to gamma emitting radionuclides in the soil. The gamma emitting radionuclides can be identified by their specific photon energies, which are registered as peaks in the spectrum. The peak count rate is related to the full absorption of unscattered gammas. If the detector is properly calibrated, the activity per unit mass for a given radionuclide of interest can be derived from the peak count rate using parameters that describe the soil characteristics (such as composition, density, and water content) and the depth profile of the distribution. The reader is referred to Beck et al. (1972), ICRU 53 (1994), Miller and Shebell (1995), and Huffert and Miller (1995) for more information on in situ gamma-ray spectrometry.

The in situ technique is particularly well suited for quickly determining levels of contamination over large areas. Each measurement provides a weighted average over the detector field of view, which is on the order of many square meters. For example, at a detector height of $1 \mathrm{~m}$, about $30 \%$ of the total fluence rate measured comes from beyond a $3-\mathrm{m}$ radius for ${ }^{137} \mathrm{Cs}$ that is uniformly distributed with depth in the soil. For a surface source distribution, about half the fluence comes from beyond $10 \mathrm{~m}$ (ICRU 1994). A series of measurements done on a grid on the order of meters apart will, therefore, provide overlapping coverage of the ground area. 
A grid spacing close enough for overlapping coverage is required to ensure that any areas of elevated activity between grid points are not missed. For an elevated area to be detected, the minimum excess peak count rate at a detector due to the elevated area must exceed the uncertainty of the measurement. That is, the elevated area has to be of enough intensity to be seen above the level of noise. In this report, it will be assumed that the in situ measurements are made close enough so that there is overlapping coverage of the ground area. For most radionuclides of interest, a separation of $5 \mathrm{~m}$ is adequate to ensure overlapping coverage.

Although a series of measurements performed on a grid provides valuable information on the spatial distribution of the contaminant, a unique continuous solution cannot be derived from the set of measurements (this observation is not restricted to data collected with the in situ technique but holds generally for any set of measurements on a grid, such as soil samples). This is an important point that can be understood intuitively, since determining a continuous distribution from a finite number of measurements without making assumptions about the distribution is clearly not possible. Difficulties will also arise due to experimental errors associated with the set of measurements.

To select one distribution among those that satisfy the data requires additional information regarding the pattern of the deposition of the radioactivity on the ground. In some special cases where the process that causes the deposition of radioactivity on the ground is well understood, making some simplifying assumptions regarding the distribution is possible. One such case is undisturbed fallout from nuclear tests where the deposition is caused by the precipitation of radioactive material from a radioactive cloud of a large size. Here, one expects deposition that is roughly constant over areas that contribute to the detector's count rate (a circle of a few meters in diameter). Using this assumption, selecting a unique distribution of activity on the ground from among the many that fit the data is then possible. However, for many cases of interest, there are no reasonable assumptions that can be made regarding the pattern of activity on the ground. These include areas for which the history of contamination is not well known, and areas where activities such as remediation can affect the level of contamination. Here, the analysis of the data might require considering many possible scenarios that fit the data and checking to see if any such distributions will exceed regulatory limits. The code ISD97 was written to implement this approach. Given a set of in situ measurements on a grid, the code ISD97 determines locations and magnitudes for potential areas of elevated activity, and for each it generates a potential distributions of activity on the ground that fit the data. In practical applications, if any of these potential distributions appear to exceed the regulatory limits, further field work (such as soil 
sampling, collimated measurements, additional measurements on a closer grid, etc.) would be used to determine whether such an elevated area was present.

D

\section{ECONVOLUTION OF INSITU MEASUREMENTS ON A GRID}

The results from a set of measurements performed over a grid can be plotted on a map and contours drawn to show variability in the count rate and to delineate elevated areas (an example of such a contour plot is shown in Figure 1). It is often assumed that the variability of activity in the ground follows the pattern of the contour plot of the count rate. This is the simplest assumption that can be made, since one can easily calculate conversion factors from count rate to deposition on the ground (using the assumption of spatial uniformity or constant activity) and then "plug in" those conversion factors to obtain deposition on the ground. In general, the distribution of activity on the ground constructed in this way will not fit the measured data, since the assumption of spatial uniformity obviously does not hold. In addition, since contour plots are constructed by interpolation there is a tendency to generate smooth distributions in this way. Contour plots will not allow for any result that exceeds the highest value measured at a grid point, and will not single out potential elevated areas that might be present between the grid points.

To illustrate the difficulties that can be encountered if one attempts to interpret a contour plot as a map of deposition on the ground, consider the simplified case of three measurements on a line. Figure 2 shows three detectors far apart with little overlap in the fields of view, while Figure 3 shows three closely spaced detectors. The use of conversion factors to calculate deposition on the ground assumes a uniform distribution over the field of view of the detector, but this assumption cannot be satisfied where the field of view of different detectors with different count rates overlap. Between measurement points one has to interpolate between different values of activity (which correspond to the different count rates of neighboring detectors), and this introduces an error. In Figure 2 where there is little overlap, the error due to this interpolation will be small, and the contour plot will provide a map of smoothed activity on the ground that fits the data. However, this is a bad setup for a survey because good overlapping coverage of the ground area is essential to assure that elevated areas that fall "between" the grid points are not missed. If we insist on having complete coverage of the ground, we must consider the case illustrated in Figure 3. Here, since there is substantial overlap in the field of view of the detectors, the error due to interpolation will be large. In summary, when the grid of 
measurements is made small enough to provide good coverage, a nonuniform distribution of activity on the ground that follows the contour plot will not fit the data.

To analyze data such as those provided in Figure 1 requires more than just preparing a contour plot. It requires carrying out a deconvolution of the data. In deconvolution, one uses the data together with a set of additional conditions to find a distribution of activity on the ground that fits the data and satisfies the given set of conditions. These additional conditions are needed because, as stated before, reconstructing the real distribution of activity on the ground from a finite number of measurements is an ill posed problem, and without additional requirements the solution is not unique. For a given distribution of activity on the ground $f(x)$, the peak count rate $N_{k}$ measured at location $k$ results from integrating the detector's response $R_{k}(x)$ over the $f(x)$, and is given by

$$
N_{k}+\epsilon_{k}=\int R_{k}(x) f(x) d x
$$

where $\epsilon_{\mathrm{k}}$ is the (unknown) measurement error, the difference between the true value and the measured value. Deconvolution of the data amounts to finding a distribution $f(x)$ of activity on the ground that fits the data (Equation 1 for all measurements) and satisfies the given set of conditions. These conditions can be mathematical (e.g., one can choose the solution to be the smoothest function that satisfies the data) or these conditions may be derived from physical considerations (e.g., one can choose the solution that is closest to a given model while still satisfying the data). An important requirement in surveying for residual radioactivity is the detection of localized areas of elevated contamination, and one possible condition that can be imposed is to require that the solutions include the largest localized areas of elevated activity suggested by the data. This is of interest since regulations limit the magnitude and size of such areas, and given a set of data one would like to know if it is possible that a localized area of elevated activity might be "hidden" within that data. The computer code ISD97 unfolds the in situ data with the use of such a condition. 


\section{T he Code ISD97}

The computer code ISD97 is a FORTRAN 90 program that generates solutions to the deconvolution problem using a two-step process. The methodology is described in detail below, but for those already familiar with the maximum entropy method it can be summarized as follows. In the first part of the code, a deconvolution of the data is carried out using the maximum entropy principle with the assumption of a constant default (background) level. The output of the maximum entropy deconvolution is an activity distribution that tends to be flat almost everywhere except in the neighborhood of each measurement point, where there will be a localized peak or a depression depending on how the measured peak count rate at that measurement point compares with the average peak count rate. This makes it possible to associate with each measurement a given level of activity in the ground that can be used to identify the location and magnitudes of potential areas of elevated activity. In the second part of the code, the maximum entropy solution is analyzed, and this information is used to find the locations and magnitudes of potential areas of elevated activity. New deconvolutions are then carried out for each potential area of elevated activity. This second series of deconvolutions are done using the maximum entropy principle with default levels set equal to a constant (background) level, plus an area of elevated activity superimposed on it. A diagram summarizing the algorithm is shown in Figure 4, and a complete listing of the code is in Appendix B.

To formulate the deconvolution problem in discrete terms, we divide the distribution of activity on the ground into a large number of equal-sized cells, the $i^{\text {th }}$ cell having activity $f_{i}$. In this way, the continuous distribution of activity on the ground $f(x)$ is approximated by point sources $f_{i}$ at each cell $\mathrm{i}$. Throughout this report we use the following notation. The peak count rate measured at point $\mathrm{k}$ is $\mathrm{N}_{\mathrm{k}}$ and $\sigma_{\mathrm{k}}$ is the statistical counting error at $1 \sigma . \mathrm{R}_{\mathrm{ki}}$ is the matrix representing the instrument response (the count rate measured at point $\mathrm{k}$ per unit activity in cell i) and $\mathrm{N}_{\mathrm{k}}=\Sigma \mathrm{R}_{\mathrm{ki}} \mathrm{f}_{\mathrm{i}}$ is the calculated peak count rate at the measurement point $\mathrm{k}$ for a given activity distribution $\mathrm{f}_{\mathrm{i}}$. We use the notation $\mathrm{f}_{\mathrm{i}}$ def to denote the default level of the cell $\mathrm{i}$ (default levels have to be specified for the maximum entropy deconvolution of the data). Finally, we use the expression "fit the data" to mean that the chi-square,

$$
\chi^{2}=\sum \epsilon_{\mathrm{k}}{ }^{2} / \sigma_{\mathrm{k}}{ }^{2}
$$


is on the order of the number of measurements (and, therefore, the distribution of activity folded with the detector response will have for each measurement an error equal on average to the uncertainty of the measurements).

The optimal cell size is determined from the following considerations: the cells must be small enough to ensure that such an approximation does not introduce a substantial error in the calculation, but large enough to reduce the total number of cells needed to model the ground and in this way reduce the computational burden. Square cells with sides measuring $50 \mathrm{~cm}$ have proven adequate to balance these two conflicting needs. The potential areas of elevated activity are modeled as squares made from $\mathrm{N}^{2}$ cells (where $\mathrm{N}$ is an integer, $\mathrm{N}=1,2, \ldots$ ). Their size is chosen by the user. This choice will depend, in general, on the regulations that are applicable to the survey area.

All the information needed for the deconvolution of the data is read in at the beginning, either by the main program or by the subroutine ISD. The code requires an input file that defines:

(a) the number of cells used to model the ground, which is modeled as a rectangle, and the size of each cell (in cm),

(b) the number of measurements, and for each measurement $k$ its coordinates $x_{k}, y_{k}$ (in $\mathrm{cm}$ ),

(c) the peak count rate $\mathrm{N}_{\mathrm{k}}$ and associated uncertainty $\sigma_{\mathrm{k}}$ (in counts $\min ^{-1}$ ) for each measurement,

(d) the photon energy being measured (in $\mathrm{keV}$ ),

(e) the detector ID code (the detector response is calculated by the subroutine RESPONSE, which includes the detector parameters), and

(f) an internal parameter used to establish a length scale for the problem (used in the subroutine PEAKXELS).

In addition, the user is prompted to enter the names of the input and output files, and the size of the potential areas of elevated activity. Finally, the user is given a choice for modeling the depth profile of the activity on the ground (uniform distribution or surface distribution), a choice of count rates to be used to set the background activity, and a choice of units to be used to report the final activity. 
Since the potential areas of elevated activity have to be superimposed over a background activity, a choice of background activity needs to be made. This background activity can be estimated from either the data or it can be entered if known a priori. The uniform background distribution is calculated from the user's choice of one of five count rate values:

(a) the average count from all measurements,

(b) the median value of the count rates,

(c) the count rate from the lowest measurement,

(d) a weighted average that minimizes the chi-square of the background distribution, and

(e) a user determined count rate.

Choice (e) is recommended if the count rate due to the background activity can be estimated a priori, for example, from a neighboring reference area, while (d) is recommended if no information regarding the background distribution is available. The other choices made available to the user can be useful under special circumstances. Selecting (d) sets the background activity for each cell equal to

$$
\mathrm{f}_{\mathrm{i}} \equiv\left(\sum \mathrm{N}_{\mathrm{k}}\left(\Sigma \mathrm{R}_{\mathrm{ki}}\right) / \sigma_{\mathrm{k}}^{2}\right) /\left(\sum\left(\Sigma \mathrm{R}_{\mathrm{ki}}\right)^{2} / \sigma_{\mathrm{k}}^{2}\right)
$$

After the initial distribution is chosen, the next step is to carry out the maximum entropy deconvolution of the data. This is done by the subroutine MAXENT, with the $f_{i}{ }^{\text {def }}$ set equal to the background level. This completes the first part of the algorithm. The results of this first part is the determination of a background activity level (which normally will not fit the data) and a maximum entropy deconvolution of the data that fits the data. As we pointed out before, the maximum entropy solution tends to be flat almost everywhere except in the neighborhood of each measurement point, where there will be a localized peak or a depression depending on how the measured peak count rate at that measurement point compares with the average peak count rate. 
In the second part of the code, the maximum entropy solution is analyzed to determine the positions and intensities of potential localized areas of elevated activity that might be present in the data. The subroutine PEAKXELS associates an integrated activity (IA) with each measurement by adding the activity that lies within a circle centered about the measurement point and subtracting from it the background activity. The circles are made as large as possible without having them overlap. The IAs will be positive or negative depending on whether there is an excess or a deficit of activity associated with that measurement point. We point out that making a quantitative correspondence between measurement points and localized activity using the peak count rates is not trivial due to the overlapping fields of view of the detectors and the nonuniformity of their response functions (which close to the measurement point varies roughly as the inverse distance squared). The assumption is made that any potential areas of elevated activity will be found in the neighborhood of those measurement points where the IA is positive. For each potential area of elevated activity, the code carries out a full analysis (as described below) that includes in each case a new deconvolution of the data.

After determining that a measurement point has a positive IA, the subroutine FINDHS is used to find the location of the area of elevated activity associated with that measurement point. This is achieved by comparing the IA at that measurement point with the IAs of the neighboring measurement points (for example, for a square grid the code compares the IA of the measurement point in question with those of the eight measurement points closest to it). FINDHS uses the inverse distance squared relationship and finds the optimal location for a point source by choosing a location that minimizes the error incurred when the activity in the IAs of neighboring measuring points is replaced by the point source (the procedure is described in more detail in the section on the subroutine FINDHS). After the positions of the potential areas of elevated activity are fixed, the magnitudes are determined by the subroutines MAGPS and MAGPSNN. The magnitude chosen is the largest one that minimizes either the chi-square of the measurements in the immediate neighborhood of the point source, or the chi-square of the measurement that is closest to the area of elevated activity. Finally, new deconvolutions are done taking into account the information on the position and magnitudes of the potential areas of elevated activity. For these final deconvolutions, the $f_{i}{ }^{\text {def }}$ are set equal to the background level plus the area of elevated activity superimposed on it. Except for the way in which $f_{j}{ }^{\text {def }}$ are chosen, the deconvolutions proceed using the maximum entropy method as described before.

The output consists of four files, one file that includes tables of results and three files that contain maps of activity distributions for plotting. The first file, which has extension "TBL," includes: 
(a) the name of the file,

(b) the detector ID code and photon energy,

(c) the average count rate and the value of the uniform activity associated with that average count rate,

(d) the background count rate and the value of the uniform activity associated with that background count rate,

(e) the chi-square of the uniform background activity distribution,

(f) the chi-square of the maximum entropy solution,

(g) parameters related to the largest potential elevated area, such as the location, magnitude, area, and the chi-square of the distribution associated with this elevated area,

(h) a table with the measured counts, calculated counts and the ratio of measured to calculated peak count rates at each measurement point for the activity distribution of the largest potential area of elevated activity, and

(i) a table with the coordinates and magnitudes of all potential areas of elevated activity, and the chi-square of the distribution associated with each elevated area.

The second file, which has extension "MXE," is the output from the maximum entropy deconvolution. The third file (which has a blank extension) is the activity distribution corresponding to the largest potential area of elevated activity over a smooth background. The fourth file, which has extension "ALL," is a collection of all the potential areas of elevated activity plotted over a smooth background. 


\section{A}

A description of the algorithms used in the most important subroutines follows.

\section{THE SUBROUTINE MAXENT}

We now present the maximum entropy deconvolution algorithm used in the code, which is a modification of the one in Wilczek and Drapatz (1985). For a discussion of the maximum entropy principle, we refer the reader to Appendix A, and to the references contained therein.

Using the notation described at the previous section, we define the set of distributions that fit the data using two restrictions:

$$
\begin{gathered}
\mathrm{N}_{\mathrm{k}}+\epsilon_{\mathrm{k}}=\sum \mathrm{R}_{\mathrm{ki}} \mathrm{f}_{\mathrm{i}}, \\
\sum \epsilon_{\mathrm{k}}{ }^{2} / \sigma_{\mathrm{k}}{ }^{2}=\Omega,
\end{gathered}
$$

where $\Omega$ is a parameter that equals the value of the $\chi^{2}$ of the solution (typically, $\Omega$ is set equal to the number of measurements), $\mathrm{k}$ labels the measurement $(\mathrm{k}=1, \ldots, \mathrm{m})$ and $\mathrm{i}$ labels the cell $(i=1, \ldots, n)$. The set of equations (4) is the discretized version of (1). Equation (5) is a $\chi^{2}$ constraint for handling the (unknown) errors $\epsilon_{\mathrm{k}}$ and assumes that the errors are normally distributed with zero mean and variances ${\sigma_{k}}^{2}$. From this set of admissible distributions we want to select the one that maximizes the entropy $S$ of the distribution,

$$
S=-\sum\left\{f_{i} \log \left(f_{i} / f_{i}{ }^{\text {def }}\right)+f_{i}{ }^{\text {def }}-f_{i}\right\}
$$

where the $\mathrm{f}_{\mathrm{i}}{ }^{\text {def }}$ is the (discretized) default distribution. Equation (6) is in the form given in Skilling (1989). 
The Lagrangian associated with the maximization of (6) with constraints (4) and (5) is of the form

$$
\begin{aligned}
\mathrm{L}\left(\mathrm{f}_{\mathrm{i}}, \epsilon_{\mathrm{k}}, \lambda_{\mathrm{k}}, \mu\right)= & -\sum\left\{\mathrm{f}_{\mathrm{i}} \log \left(\mathrm{f}_{\mathrm{i}} / \mathrm{f}_{\mathrm{i}} \text { def }\right)+\mathrm{f}_{\mathrm{i}}{ }^{\text {def }}-\mathrm{f}_{\mathrm{i}}\right\} \\
& -\sum \lambda_{\mathrm{k}}\left\{\sum \mathrm{R}_{\mathrm{ki}} \mathrm{f}_{\mathrm{i}}-\mathrm{N}_{\mathrm{k}}-\epsilon_{\mathrm{k}}\right\}-\mu\left\{\sum\left(\epsilon_{\mathrm{k}} / \sigma_{\mathrm{k}}\right)^{2}-\Omega\right\} .
\end{aligned}
$$

where $\lambda_{\mathrm{k}}, \mu$ are $(\mathrm{m}+1)$ Lagrange multipliers. Variation with respect to $f_{i}, e_{k}$ and $\mu$ lead to the set of $(n+m+1)$ equations

$$
\begin{gathered}
-\log \left(f_{\mathrm{i}} / \mathrm{f}_{\mathrm{i}}{ }^{\mathrm{def}}\right)-\sum \lambda_{\mathrm{k}} \mathrm{R}_{\mathrm{ki}}=0 \\
\lambda_{\mathrm{k}}-2 \mu \epsilon_{\mathrm{k}} / \sigma_{\mathrm{k}}{ }^{2}=0 \\
\sum \epsilon_{\mathrm{k}}{ }^{2} / \sigma_{\mathrm{k}}{ }^{2}=\Omega
\end{gathered}
$$

We can use (8), (9) and (10) to solve for the $f_{i}$, the $\epsilon_{k}$ and $\mu$ in terms of the $\lambda_{k}$,

$$
\begin{gathered}
\mathrm{f}_{\mathrm{i}}=\mathrm{f}_{\mathrm{i}}{ }^{\operatorname{def}} \exp \left\{\sum \lambda_{\mathrm{k}} \mathrm{R}_{\mathrm{k} i}\right\} \\
\epsilon_{\mathrm{k}}=\lambda_{\mathrm{k}} \sigma_{\mathrm{k}}{ }^{2} / 2 \mu \\
\mu=\left(\sum\left(\lambda_{\mathrm{k}} \sigma_{\mathrm{k}}\right)^{2} / 4 \Omega\right)^{1 / 2} .
\end{gathered}
$$

Variation with respect to the $\lambda_{\mathrm{k}}$ leads to (4), and using (11), (12), and (13) we can write these $m$ equations as

$$
\mathrm{N}_{\mathrm{k}}+\lambda_{\mathrm{k}} \sigma_{\mathrm{k}}^{2}\left(\Omega / \sum\left(\lambda_{\mathrm{j}} \sigma_{\mathrm{j}}\right)^{2}\right)^{1 / 2}-\sum \mathrm{R}_{\mathrm{kj}} \mathrm{f}_{\mathrm{j}}^{\text {def }} \exp \left\{\sum \lambda_{\mathrm{l}} \mathrm{R}_{\mathrm{lj}}\right\}=0
$$


Thus, the initial optimization problem stated has been reduced to a system of $m$ equations with $\mathrm{m}$ unknowns $\lambda_{1}, \ldots, \lambda_{\mathrm{m}}$. These equations can also be derived by maximizing a potential function $\mathrm{Z}$,

$$
Z=-\sum \mathrm{f}_{\mathrm{i}}{ }_{\mathrm{def}} \exp \left\{-\sum \lambda_{\mathrm{k}} \mathrm{R}_{\mathrm{ki}}\right\}-\left(\Omega \sum\left(\lambda_{\mathrm{k}} \sigma_{\mathrm{k}}\right)^{2}\right)^{1 / 2}-\sum \mathrm{N}_{\mathrm{k}} \lambda_{\mathrm{k}}
$$

with respect to the $\lambda_{\mathrm{k}}$. Therefore, we can reformulate the problem in terms of the maximization of the potential function $\mathrm{Z}$.

The $f_{i}{ }^{\text {def }}$ are default levels for each cell $i$. Without the chi-square constraint, the maximum entropy solution would default to $f_{i}=f_{i}$ def . When the subroutine MAXENT is called the first time, the $\mathrm{f}_{\mathrm{i}}$ def are set equal to a constant, background activity distribution. When it is called for the final deconvolutions (after the initial magnitude of each of the potential areas of elevated activities are determined by the subroutines MAGPS and MAGPSNN), the $f_{i}$ def are set equal to a background level plus an area of elevated activity superimposed on it.

To find the extremum of the potential function $Z$, we use the subroutines FRPRMN and LMBDAS. FRPRMN is more robust while LMBDAS converges more quickly. For the deconvolution that gives us the maximum entropy map, we first use FRPRMN with the initial value of the $\lambda_{\mathrm{k}}$ set equal to zero, and then restart the maximization using LMBDAS. For all other deconvolutions, we use LMBDAS with the initial value of the $\lambda_{k}$ set equal to the values that correspond to the maximum entropy solution. If LMBDAS stops converging the deconvolution proceeds using FRPRMN.

\section{THE SUBROUTINE LMBDAS}

This subroutine uses an iterative procedure based on the integral equations (14) from which follow the set of equations

$$
\lambda_{k}{ }^{\mathrm{M}+1}=(1-\mathrm{p}) \lambda_{\mathrm{k}}{ }^{\mathrm{M}}+\mathrm{p}\left(\sum \mathrm{R}_{\mathrm{kj}} \mathrm{f}_{\mathrm{j}}^{\mathrm{def}} \exp \left\{\sum \lambda_{1}{ }^{\mathrm{M}} \mathrm{R}_{\mathrm{lj}}\right\}-\mathrm{N}_{\mathrm{k}}\right)\left(\sum\left(\lambda_{\mathrm{j}}{ }^{\mathrm{M}} \mathrm{\sigma}_{\mathrm{j}}\right)^{2} / \Omega\right)^{1 / 2} / \sigma_{\mathrm{k}}{ }^{2}
$$


where $\mathrm{M}$ denotes the $\mathrm{Mth}$ iterate. The parameter $\mathrm{p}$ is a smoothing parameter introduced to help convergence. It is set initially to 0.01 and allowed to increase to up to 0.1 in successive iterations. This iterative procedure requires initial values $\lambda_{\mathrm{j}}^{0}$ satisfying

$$
\sum\left(\lambda_{\mathrm{j}}^{0} \sigma_{\mathrm{j}}\right)^{2} \neq 0
$$

\section{THE SUBROUTINE FRPRMN}

This subroutine is taken from Press et al. (1992). Given a set of initial values for the $\lambda_{k}$, it uses the conjugate gradient method in multidimensions to maximize the potential function $\mathrm{Z}$.

\section{THE SUBROUTINE PEAKZELS}

This subroutine calculates the excess or deficit of activity associated with each measurement position. The IA associated with each measurement is calculated by adding the activity that lies within a circle centered about the measurement point and subtracting from it the background activity $f_{i}^{B K G}$,

$$
\mathrm{IA}_{\mathrm{k}}=\sum\left\{\mathrm{f}_{\mathrm{i}}-\mathrm{f}_{\mathrm{i}}^{\mathrm{BKG}}\right\}
$$

where the sum is over the $f_{i}$ within the circle, centered about the measurement position $k$. The circles are made as large as possible without having them overlap. The IAs will be positive or negative depending on whether there is an excess or a deficit of activity associated with that measurement point.

\section{THE SUBROUTINE FINDHS}

This subroutine calculates the optimal position of the potential area of elevated activity. To find this position, we use the following reasoning. If measurements at neighboring measurement points are in fact due to a single localized area of elevated activity, then it should be possible to replace the IAs of these measurement points with excess activity at a single location and still have a distribution that fits the data. 
To carry out this procedure, the potential localized area of elevated activity is approximated by a point source. For each neighboring measurement point $k$, and for a point source of activity $A_{e}$ located at an arbitrary point $e$, we now define an error term $\delta_{e k}$ using the equation

$$
\sum\left(\mathrm{IA}_{j} / \mathrm{r}_{\mathrm{jk}}{ }^{2}\right)=\left(\mathrm{A}_{\mathrm{e}}+\delta_{\mathrm{ek}}\right) / \mathrm{r}_{\mathrm{ek}}{ }^{2}
$$

where $I A_{j}$ is the integrated activity of measurement point $j, r_{e k}$ is the distance between the cells $e$ and $\mathrm{k}$, and the sum is over the measurement points close to the area of elevated activity. Here, we have taken into account the fact that the detector response for a point source can be approximated by the inverse distance squared relationship. For a given location e, the activity $\mathrm{A}_{\mathrm{e}}$ is found by minimizing the magnitude of the error term vector $E_{e}$ associated with the point $e$, which we define as

$$
\mathrm{E}_{\mathrm{e}}=\left(\sum \delta_{\mathrm{ek}}^{2}\right)^{1 / 2}
$$

By systematically calculating $\mathrm{E}_{\mathrm{e}}$ for different locations e close to $\mathrm{k}$, one can determine the location at which it is a minimum, and in this way define the optimal position of the potential area of elevated activity. While this procedure involves introducing approximations and it is, therefore, not exact, it has been found to be reliable and to lead to good results.

\section{THE SUBROUTINE MAGPS}

This subroutine calculates the optimal intensity of the potential area of elevated activity. The area of elevated activity is modeled with a point source at cell e superimposed on a flat background, and the activity of the point source is calculated by minimizing the chi-square of the measurements in the immediate neighborhood of the point source.

\section{THE SUBROUTINE MAGPSNN}

This subroutine provides an alternative calculation of the optimal intensity of the point source used in the modeling of a potential area of elevated activity. The area of elevated activity is modeled with a point source at cell e superimposed on a flat background, and the activity of the 
the point source is calculated by minimizing the chi-square for the measurement that is nearest to the point source only. The value of the activity calculated by MAGPSNN is used only when it exceeds the activity calculated by MAGPS.

\section{THE SUBROUTINE RESPONSE}

This subroutine contains all the relevant information on the instrument response (the count rate per unit activity) for the detectors used, and calculates the response matrix $R_{k i}$. Currently, the calculation of the response matrix takes into account the inverse distance squared relationship, the photon energy, the photon attenuation in air and ground, detector parameters related to the efficiency and angular response, and a choice of either a uniform or a surface source distribution to model the distribution in depth. This subroutine is in a separate file, and can be easily modified and updated.

\section{$\Upsilon_{\text {eST CASES }}$}

The computer code ISD97 has been tested using both simulated data and actual measurements. In this section we summarize results obtained with data from two different field measurements.

\section{TEST CASE Number ONE}

We summarize the results of an analysis of a series of field measurements where a $28.23 \mathrm{kBq}$ ${ }^{137} \mathrm{Cs}$ check source was used to simulate an area of elevated activity. The results described here differ from the analysis in Reginatto et al. (1996) due to a number of improvements that have since been incorporated into the code. In particular, the maximum entropy algorithm and the subroutines that calculate the position and magnitude of the potential areas of elevated activity have been rewritten, resulting in better agreement between the parameters calculated by the code and the actual position and magnitude of the check source used to simulate the area of elevated activity.

The field site chosen was nonuniform, including some areas that had been resurfaced. The

${ }^{137} \mathrm{Cs}$ background distribution varied between close to zero and its expected global fallout level in this area $\left(2.96 \mathrm{kBq} \mathrm{m}^{-2}\right)$. Measurements were made with a $40 \%$ relative efficiency germanium 
detector placed at a height of $1 \mathrm{~m}$, with a counting time of $10 \mathrm{~min}$ at each measurement point. Thirty-five equally spaced measurements of the $662 \mathrm{keV} \gamma$ fluence were taken on a rectangular $7 \times 5$ grid. The measurement points were $2.44 \mathrm{~m}(8 \mathrm{ft})$ apart. The statistical uncertainty was $<5 \%(1 \sigma)$ for each measurement. The peak count rate at different measurement points varied by up to a factor of eight due to the variability of the background and to some extent also to the presence of the area of elevated activity. The data was processed in two different ways. In one case, all 35 measurements were taken into account. In the other, every other measurement was discarded, resulting in a total of 12 measurements on a $4 \times 3$ rectangular grid with a spacing of $4.88 \mathrm{~m}$ (16 ft). For the deconvolution, the area of elevated activity was modeled as one cell, a square $0.4 \mathrm{~m} \times 0.4 \mathrm{~m}$ in size.

Figure 1 shows the peak count rate measured at each measurement point in the grid, along with a contour plot constructed from the data by interpolation. The position of the check source is also shown. It is common practice to assume that the activity on the ground follows a similar contour pattern. As pointed out before, this approximation is not valid when there is good overlap of the field of view of the detectors. For our test case, this is certainly not so, and the contour plot does not provide a good map of the underlying activity distribution that will fit the data. Figure 5 shows the output from the maximum entropy deconvolution, while Figure 6 is the activity distribution that corresponds to the largest single potential area of elevated activity over a smooth background for the 35 measurements case. Both types of deconvolutions generate good solutions in the sense that in both cases the activity distributions fit the data. The maximum entropy solution shows structure that reflects the grid geometry with peaks centered exactly at measurement points with an excess of activity. The solution with the largest area of elevated activity on the other hand has one large peak that falls between measurement points superimposed on a smooth background.

The code located the potential area of elevated activity very precisely, within $22 \mathrm{~cm}$ of the actual location of the check source when using 35 measurements, and within $37 \mathrm{~cm}$ when using 12 measurements (the code also provided locations for other potential areas of elevated activity that turned out to be related to areas that had higher levels of activity due to variations in background activity, but we will restrict this discussion to the potential area of elevated activity that corresponds to the check source). The code was also very successful in estimating the magnitude of the point source. The calculated magnitude of the point source was $26.93 \mathrm{kBq}$ (within $5 \%$ of the true value) when using 35 measurements, and $75.84 \mathrm{kBq}(2.7$ times the true value) when using 12 measurements. The 12 measurements case is less constrained, and, therefore, allows for a larger potential area of elevated activity. 


\section{Test Case Number Two}

We summarize an analysis of in-situ measurements in a room that had ${ }^{137} \mathrm{Cs}$ contamination on the floor. The floor of the room was rectangular and measured $5.0 \mathrm{~m} \times 6.0 \mathrm{~m}$. Four measurements at $662 \mathrm{keV} \gamma$ fluence with a counting time of $10 \mathrm{~min}$ were taken with a $40 \%$ relative efficiency germanium detector placed at a height of $1 \mathrm{~m}$. To set up the grid, the floor was divided into four quadrants with a measurement centered in each. The statistical uncertainty was on the order of $5 \%$ for each measurement, and the peak count rate at different measurement points varied by up to a factor of three due to the presence of the contaminant. In addition to these measurements, 22 collimated measurements taken with the detector placed close to the ground and using a collimator that restricted the field of view to a circle of $35 \mathrm{~cm}$ in radius. These collimated measurements were not analyzed with the code ISD97, but were used instead to construct a map of localized activity that can be compared with the results of the deconvolution of the four uncollimated measurements. For the deconvolution, the area of elevated activity was modeled as a square $1.0 \mathrm{~m} \times 1.0 \mathrm{~m}$ in size. The background level (which was essentially zero) was set equal to the statistical uncertainty. Further details can be found in Miller et al. (1997).

Figure 7 shows a map of the floor with peak count rates plotted for both uncollimated and collimated measurements, and the location of the four uncollimated measurements. In addition, the location of the potential elevated area identified by the code is shown. Although the contamination appears to extend over an irregular area of more than one square meter, the location of the area of elevated activity identified by the code corresponds with good precision to the contaminated area. The code was also very successful in estimating the magnitude of the elevated area. The activity calculated by the code from the four uncollimated measurements equals $0.41 \mathrm{~Bq}$, while the activity derived from the four highest collimated measurements in the neighborhood of the elevated area equals $0.48 \mathrm{~Bq}$ (the total inventory calculated from all measurements equals $0.52 \mathrm{~Bq}$ ).

The data from a few uncollimated measurements, when analyzed with the code ISD97, can provide information that would otherwise require many collimated measurements. Use of this methodology can, therefore, result in substantial savings in time and expense. 


\section{ONCLUSIONS}

In this report we describe in detail the code ISD97, a computer program that analyzes data from a series of in situ measurements on a grid and identifies potential areas of elevated activity. Due to the nonuniqueness of the deconvolution problem, we do not search for a single solution that fits the data, but have developed instead a methodology in which we search for many distributions of activity on the ground, all of which fit the data and have a potential area of elevated activity. This approach seems to be the only one adequate for areas for which the history of contamination is not well known, as well as for areas where activities such as remediation can affect contamination in unforeseeable ways, since then there are no reasonable assumptions that will select one solution from all the possible solutions that fit the data.

The methodology presented here provides an alternative to the standard methods of detecting areas of elevated activity. Of the methods currently in use, one of the most common is a "walkover" using a survey meter gross count rate to signal the presence of an area of high radioactivity. These surveys depend to some extent on the expertise of the technician doing the "walkover" and (unlike regulations) do not discriminate between different radionuclides. The results of such surveys are, therefore, more qualitative than quantitative. The method implemented in the code ISD97 uses in situ data taken under controlled conditions. It provides the location of potential areas of elevated activity consistent with the data, and it lists activity levels for all the potential areas of elevated activity found. In this way a quantitative record of the magnitude of areas of elevated activity that might be "hidden" in the data is generated. Analyses of data from actual field measurements (two of which are summarized in this report) show that the methodology is directly applicable to practical cases. 


\section{$\mathbf{R}_{\text {EFERENCES }}$}

Beck, H. L., J. De Campo and C. K. Gogolak

In Situ $\mathrm{Ge}(\mathrm{Li})$ and $\mathrm{NaI}(\mathrm{Tl})$ Gamma-Ray Spectrometry

U.S. Atomic Energy Commission, New York, Report HASL-258 (1972)

Huffert, A. M. and K. M. Miller

Measurement Methods for Radiological Surveys in Support of New Decommissioning Criteria NUREG-1506 (Draft Report for Comment), Washington, D.C.: Nuclear Regulatory Commission (1995)

International Commission on Radiation Units and Measurements

Gamma-Ray Spectrometry in the Environment

Bethesda, MD: ICRU Publication 53 (1994)

Jaynes, E. T.

Information Theory and Statistical Mechanics

Phys. Rev. 106:620-630 (1957)

Jaynes, E. T.

Prior Probabilities

IEEE Trans. Syst. Cybern. SSC-4:227-241 (1968)

Miller, K. M. and P. Shebell

In Situ Gamma-Ray Spectrometry - A Tutorial for Environmental Radiation Scientists

USDOE Report EML-557 (1995)

Miller, K. M., M. Reginatto, P. Shebell, G. A. Klemic, and C. V. Gogolak

Spectrometric Techniques for the Measurement of Radioactive Contamination in Buildings Proceedings Air and Waste Management Association's $90^{\text {th }}$ Annual Meeting and Exhibition Toronto, Ontario, Canada, June 8-13 (1997)

Press, W. H., S. A. Teukolsky, W. T. Vetterling and B. P. Flannery Numerical Recipes in FORTRAN: the Art of Scientific Computing Cambridge University Press, New York, NY, Second Edition (1992) 
Reginatto, M., P. Shebell and K. M. Miller

An Application of the Maximum Entropy Method for Assessments of Residual Radioactivity at Contaminated Sites

IEEE Trans. Nucl. Sci. 43:1837-1841 (1996)

Shannon, C. E.

A Mathematical Theory of Communication

Bell Syst. Tech. J. 27:379-423, 623-656 (1948)

Shore, J. E. and R. W. Johnson

Axiomatic Derivation of the Principle of Maximum Entropy and the Principle of Minimum Cross-Entropy

IEEE Trans. Info. Theory IT-26: 26-39 (1980)

Skilling, J.

Classic Maximum Entropy

In: J. Skilling (Editor), Maximum Entropy and Bayesian Methods

Kluwer Academic Publishers, Dordrecht (1989)

Wilczek, R. and S. Drapatz

A High Accuracy Algorithm for Maximum Entropy Image Restoration in the Case of Small Data Sets

Astron. Astrophys. 142: 9-12 (1985) 


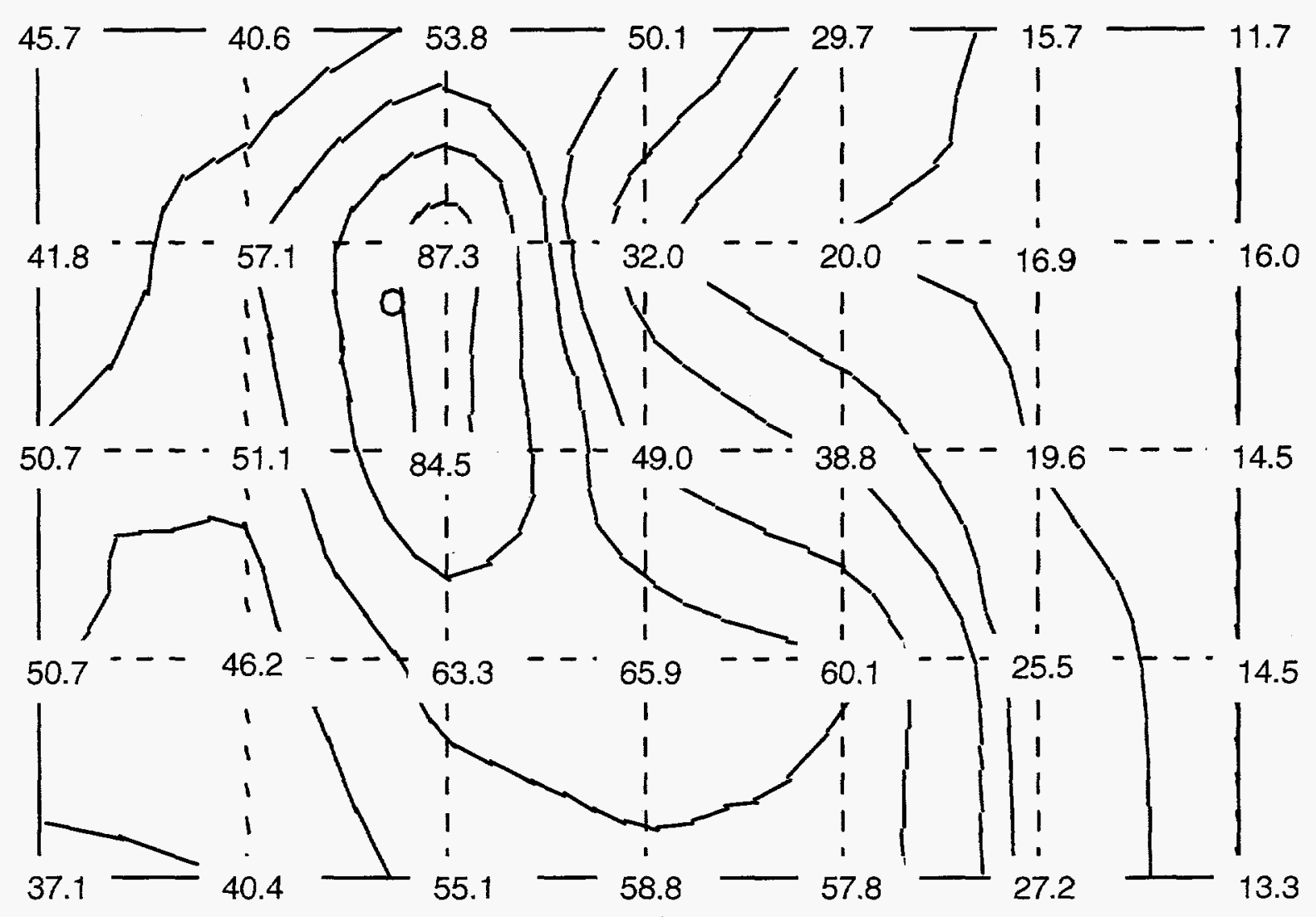

Figure 1. Grid with peak count rates (counts $\mathrm{min}^{-1}$ ) at each measurement point. The circle indicates the placement of a check source used to simulate an elevated area. 

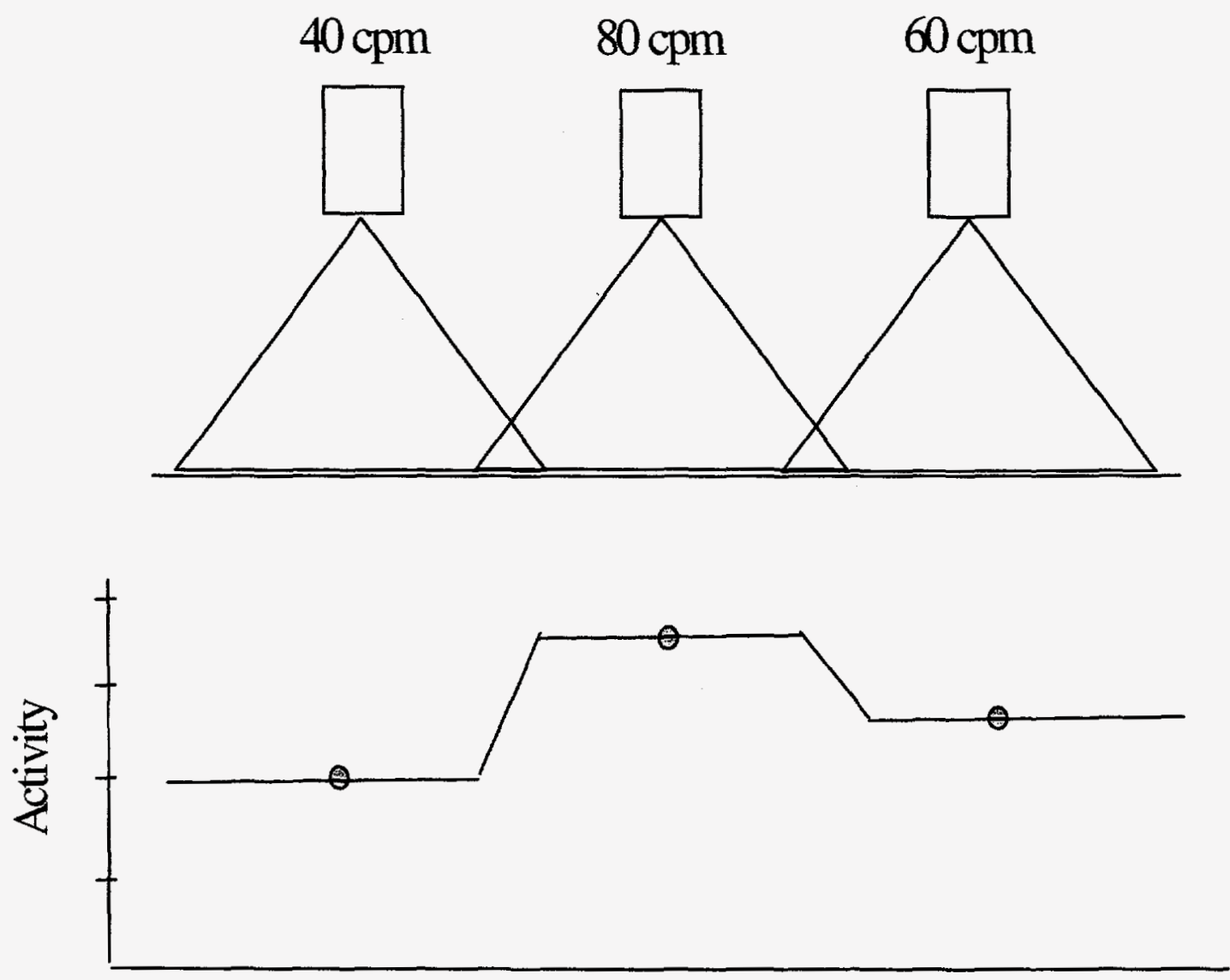

Figure 2. Map of activity on the ground (constructed from the count rate contour plot) for three detectors with little overlap. 


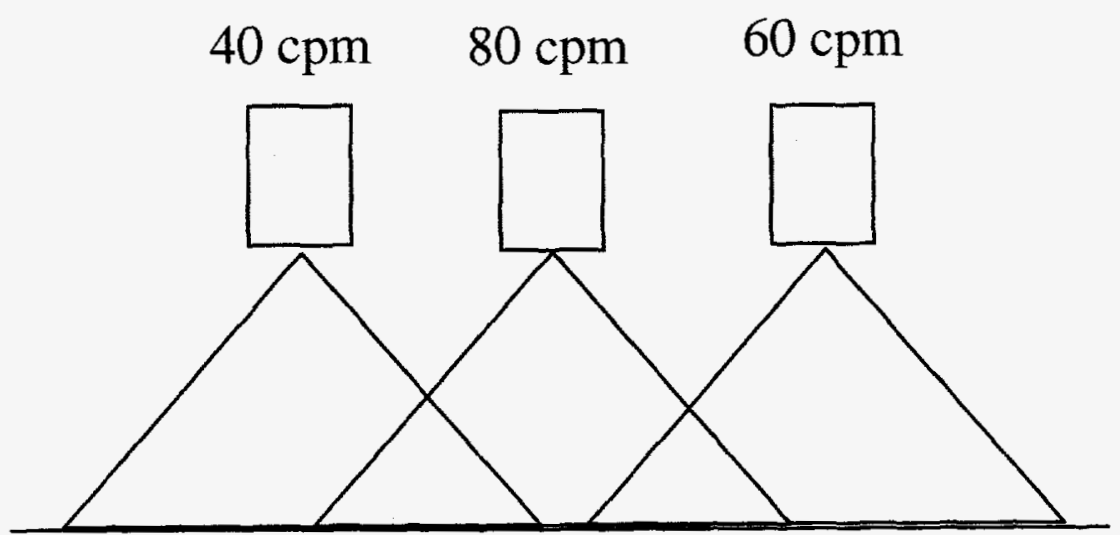

党

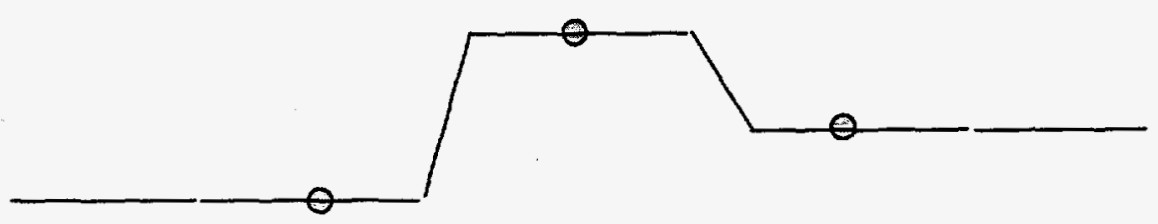

Figure 3. Map of activity on the ground (constructed from the count rate contour plot) for three closely spaced detectors. 


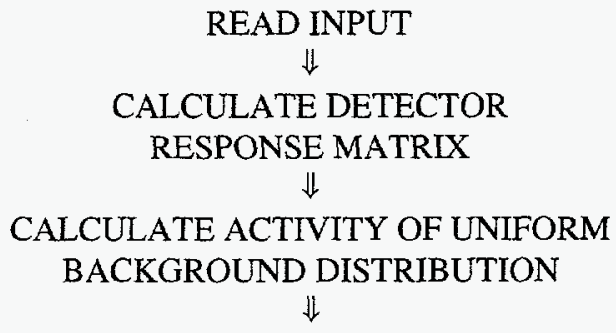

CALCULATE MAXIMUM ENTROPY SOLUTION (MAXIMUM ENTROPY DECONVOLUTION WITH DEFAULT DISTRIBUTION = BACKGROUND) $\Downarrow$

FOR ALL MEASUREMENT POINTS CALCULATE INTEGRATED ACTIVITY (IA) FROM THE MAXIMUM ENTROPY SOLUTION $\Downarrow$ FOR MEASUREMENT POINTS WITH IA $>0$ CALCULATE POSITION OF POTENTIAL ELEVATED AREA $\Downarrow$ FOR MEASUREMENT POINTS WITH IA $>0$ CALCULATE MAGNITUDE OF POTENTIAL ELEVATED AREA $\Downarrow$ FOR MEASUREMENT POINTS WITH IA $>0$ PLACE POTENTIAL ELEVATED AREA OVER BACKGROUND $\Downarrow$ FOR MEASUREMENT POINTS WITH IA $>0$ CALCULATE ACTIVITY DISTRIBUTION THAT FITS DATA AND CONTAINS A POTENTIAL ELEVATED AREA (MAXIMUM ENTROPY DECONVOLUTION WITH DEFAULT DISTRIBUTION = BACKGROUND + POTENTIAL ELEVATED AREA) \# IDENTIFY LARGEST POTENTIAL ELEVATED AREA $\Downarrow$ WRITE OUTPUT

Figure 4. Algorithm of code ISD97. 


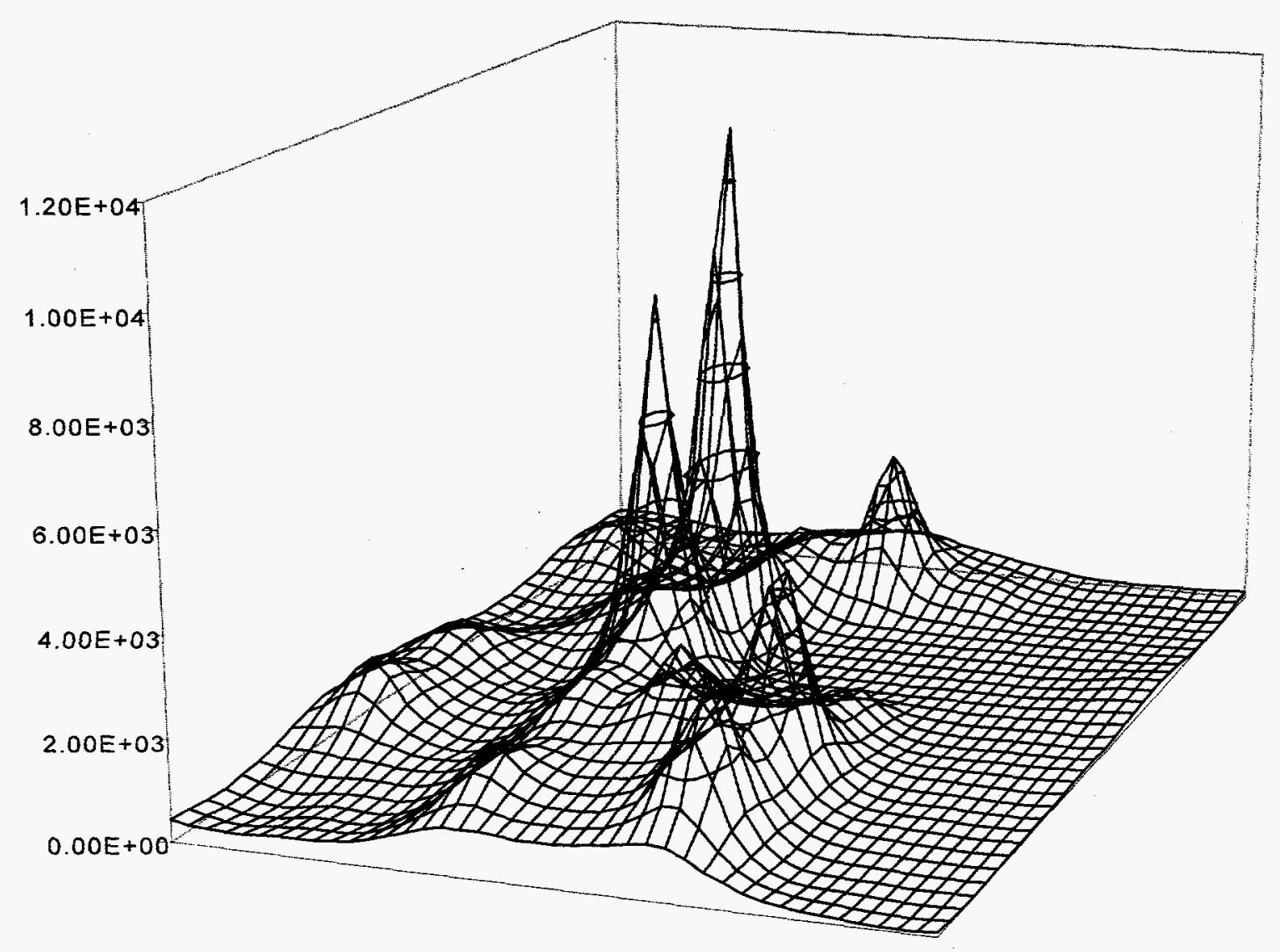

Figure 5. Activity distribution $\left(\mathrm{Bq} \mathrm{m}^{-2}\right)$ from maximum entropy deconvolution (test case 1). 


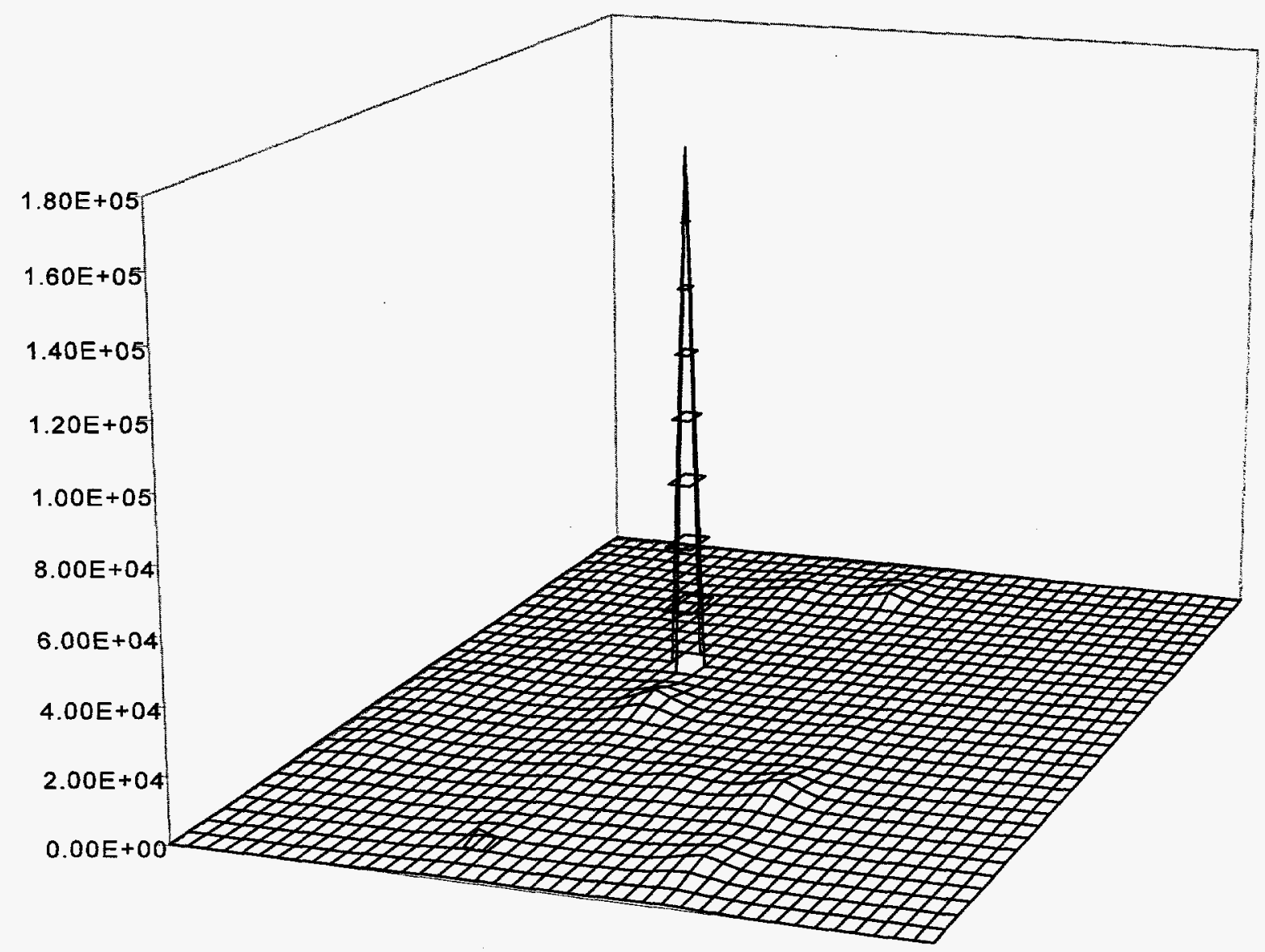

Figure 6. Activity distribution $\left(\mathrm{Bq} \mathrm{m}^{-2}\right)$ for largest potential area of elevated activity (test case 1). 

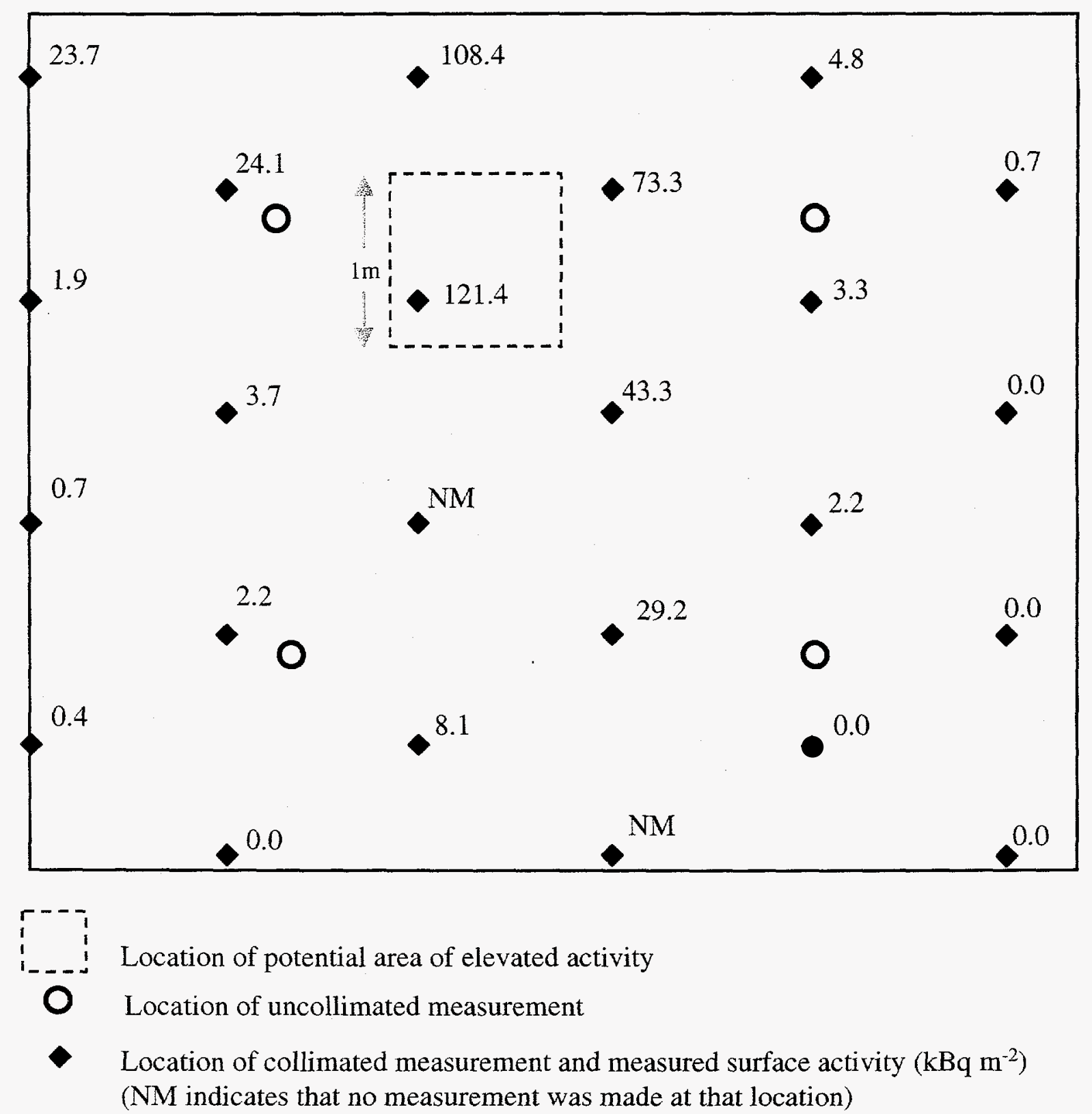

Figure 7. Analyses of in situ measurements in a $5 \mathrm{~m} \mathrm{x} 6 \mathrm{~m}$ room with ${ }^{137} \mathrm{Cs}$ contamination on the floor (test case 2). Data from collimated measurements, location of uncollimated measurements, and location of potential area of elevated activity identified by the code. 


\section{THE PRINCIPLE OF MAXIMUM ENTROPY}

The entropy of the distribution $\mathrm{f}(\mathrm{x})$, in the form given in Skilling (1989), is given by

$$
S=-\int\left\{f(x) \log \left(f(x) / f(x)^{\operatorname{def}}\right)+f(x)^{\text {def }}-f(x)\right\} d x
$$

where $f(x)^{\text {Def }}$ is the default distribution. This is a generalization of the usual cross-entropy formula

$$
S_{C E}=-\int\left\{f(x) \log \left(f(x) / f(x)^{\operatorname{def}}\right)\right\} d x,
$$

which appears as the first term in (A.1). The second term in (A.1) is an additive constant that ensures that the global maximum of $S\left(\right.$ at $\left.f(x)=f(x)^{d e f}\right)$ is zero, a sometimes convenient but not essential requirement. The third term in (A.1) ensures that in the absence of any other constraints $S$ is maximized at $f(x)=f(x)^{\text {def }}$ (rather than just being proportional).

Before we go on, a note on terminology: some authors use the term entropy when referring to what we call here cross-entropy, while others use the term cross-entropy for the negative of $S_{C E}$ and as a result end up with the principle of minimum cross-entropy. Other names for $\mathrm{S}_{\mathrm{CE}}$ (or its negative) are relative entropy, direct divergence, expected weight of evidence, Kullback-Leibler distance, and Kullback number. To add to the confusion (and to keep the arguments as close to the standard literature as possible), when discussing the maximum entropy principle in this section, we will be referring to maximization of $\mathrm{S}_{\mathrm{CE}}$, not of $\mathrm{S}$. For an axiomatic derivation of $\mathrm{S}$ (rather than $\mathrm{S}_{\mathrm{CE}}$ ), we refer the reader to Skilling (1989).

Historically, the concept of entropy originated in thermodynamics, but its generalization plays an important role in information theory, probability theory, and statistical inference. The maximum entropy principle provides a rule for determining a positive, additive distribution given definite but incomplete constraints. The probability distribution $\operatorname{pr}(\mathrm{x})$ of a variable $\mathrm{x}$ is an 
example of a positive, additive distribution. It is positive by construction, and it is additive in the sense that the overall probability in a domain equals the sum of the probabilities in any decomposition into subdomains. In our case, the positive, additive distribution to be determined is the distribution of activity $f(x)$, and the constraints are the measurements and the experimental errors associated with them. The maximum entropy principle states that one should choose from all of the distributions $f(x)$ that satisfy the set of constraints the one for which $S_{C E}$ is maximal. $A$ parallel procedure is used in statistical mechanics, where given constraints on the total energy and number of particles of a gas, entropy maximization is used to infer a distribution that is uniform in space and Maxwellian in velocity. There are several approaches that lead to the maximum entropy principle, and we summarize two of them below.

In the original derivation by Jaynes $(1957,1968)$, the use of the maximum entropy principle is justified on the basis of the cross-entropy's unique properties as an uncertainty measure. Arguments originating in information theory show that the Shannon entropy,

$$
S_{\mathrm{SH}}=-\sum \mathrm{f}_{\mathrm{i}} \log \left(\mathrm{f}_{\mathrm{i}} / \mathrm{f}_{\mathrm{i}}^{\mathrm{def}}\right)
$$

is the appropriate measure of the amount of uncertainty expressed in a distribution. These arguments follow from requiring three consistency conditions that are generally accepted as requirements for an uncertainty measure. Expression (A.3) for the case $f_{i}{ }^{\text {def }}=1$ was originally derived by Shannon (1948) for discrete distributions. Jaynes (1968) showed that (A.2) can be derived by generalizing to continuous distributions, in which case $f(x)$ def appears as an "invariant measure" function (as well as playing the role of default distribution). Once a measure of the amount of uncertainty is established, it then seems reasonable to choose from all distributions $f(x)$ satisfying a set of constraints the one for which $S_{C E}$ is maximal, since this is the distribution that "assumes the least" about the unknown $f(x)$. While agreeing with what is known, it will be maximally noncommittal with regard to all information except the data, and, therefore, the most unbiased estimate.

An independent justification that makes no reference to information theory is given by Shore and Johnson. Jaynes (1957) had already remarked that inferences made using any other information measure than the entropy may lead to contradictions. Shore and Johnson (1980) considered the consequences of requiring that methods of inference be self-consistent. They introduced four axioms that were all based on one fundamental principle: if a problem can be 
solved in more than one way, the results should be consistent. Informally, they stated their axioms as follows:

1. Uniqueness: The result should be unique,

II Invariance: The choice of coordinate system should not matter,

III. System independence: It should not matter whether one account for independent information about independent systems separately in terms of different densities or together in terms of a joint density, and

IV. Subset independence: It should not matter whether one treats an independent subset of system states in terms of a separate different conditional density or in terms of the full system density.

Shore and Johnson go on to show that given information in the form of a set of constraints on expected values, there is only one distribution satisfying the set of constraints that can be chosen by a procedure that satisfies the four axioms, and this unique distribution can be obtained by maximizing $\mathrm{S}_{\mathrm{CE}}$. Therefore, if a method of inference is based on a variational principle, maximizing any function but the cross-entropy will lead to inconsistencies unless that function and entropy have identical maxima (any monotonic function of the entropy will work, for example). 


\section{$\mathbf{A}_{\text {Prenox }}$}

\section{LISTING OF THE PROGRAM ISD97}

PROGRAM ISD97

C

C A computer program that analyzes data from a series of in situ

$C$ measurements on a grid and identifies potential localized areas

C of elevated activity.

C

INTEGER M,NX,NY, NXY, MNXY, ISP

INTEGER DETNUM,PE

INTEGER MNUM(1000)

REAL A.HSA

REAL D(1000),S(1000),X(1000),Y(1000)

CHARACTER DH*8, EH*8

COMMON/AISP/A, ISP

COMMON/MN/M, NX, NY, MNXY, NXY

C

C

PRINT*.' NAME OF FILE WITH INPUT DATA? (USE 8 CHARACTERS) :

$R E A D^{*}, D H$

PRINT*.' NAME OF OUTPUT FILE? (USE 8 CHARACTERS) : '

$R E A D *, E H$

PRINT*,' AREA OF ELEVATED AREA? (IN SQUARE METERS, e.g.: 1.0) : ' $R E A D^{*}, H S A$

C Next the following data is read in from the file $D H$ :

$C$ (1) $M$ is the number of measurements

$C$ (2) The ground is made up of (NX,NY) cells.

C (3) A is the size of each cell (in $\mathrm{cm}$ ).

C (4) ISP is used by several subroutines. It is set up

C normaliy equal to one half the number of cells between

C measurements (or slightly more if the number of cells between

$c$ measurements is not even). Must have ISP $>0$. ISP is used in

$c$ the subroutine PEAKXELS to fix the radius of the circle on which 
C the integration over counts is done.

C (5) DETNUM is the detector number.

$C$ (6) PE is an integer, the photon energy.

C (7) MNUM is the measurement number. Must Have MNUM(I) $>0$.

C (8) X,Y are the coordinates of measurements (in $\mathrm{cm}$ ).

C (9) D are the measurements (in cpm).

C (10) S are the corresponding sigmas for each measurement.

C

OPEN (11, FILE=DH, STATUS='OLD' $)$

C

READ $(11, F M T=*) M, N X, N Y$

$\operatorname{READ}(11, F M T=*) A$

READ (11, FMT $=*)$ ISP

READ (11, FMT $=*)$ DETNUM

$\operatorname{READ}(11, \mathrm{FMT}=*)$ PE

DO $1 \mathrm{I}=1, \mathrm{M}$

$\operatorname{READ}(11, F M T=*) \operatorname{MNUM}(I), X(I), Y(I), D(I), S(I)$

1 CONTINUE

CLOSE (11)

C

$M N X Y=M * N X * N Y$

$N X Y=N X * N Y$

C

CALL ISD(DH, EH, HSA, X, Y, D , S, DETNUM, PE, MNUM)

C

END

C

C

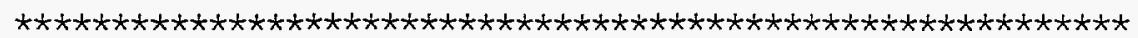

SUBROUTINE ISD(DH, EH, HSA, X, Y, D, S, DETNUM, PE, MNUM)

C

INTEGER I, I I, K, L, IG

INTEGER IHP, KL, KU, LL, LU

INTEGER M, NX, NY, NXY, MNXY, ISP, HSS, G1, G2

INTEGER DETNUM, PE, NSD, NUM

INTEGER MNUM(1000)

REAL C, T, Z, ZAVG, MM, C1, CZ, CME

REAL HHP, PP, CSQ

REAL A, HHPNN, HSA 
REAL DAVG, DBKG, SB, XMAX, XMIN, YMAX, YMIN, PPMCF, EAM, SUM1, SUM2

REAL D(M),DSORT (M),EZ(M),E(M),S(M),F(NXY)

REAL ERR(M), FP(NXY), PFE(M), RKHS (M), RLHS(M)

REAL MHS(M), CHISQ(M)

REAL $B(M N X Y), X(M), Y(M), Z K L(N X Y)$

REAL ZKLP(NXY)

REAL FPF (NXY), EF(M)

REAL FMAP (NXY)

REAL LAMBDA(M), LME (M), BI (M)

CHARACTER $\mathrm{DH} * 8, \quad \mathrm{EH} * 8, \mathrm{CH} * 12, \mathrm{TH} * 12, \mathrm{WH} * 12$

CHARACTER UNITS* 10

COMMON/AISP/A, ISP

COMMON/MN/M,NX,NY,MNXY,NXY

C

$H S S=F L O O R((S Q R T(H S A)) /(0.01 * A))$

$H S A=(0.01 * A * H S S) * * 2$

PRINT*,' AREA OF ELEVATED AREA (IN SQUARE METERS) SET TO : ' HSA PRINT* ' '

C

$M M=F L O A T(M)$

C

C The user has a choice of two source distributions.

C

PRINT*', SOURCE DISTRIBUTION? (UNIFORM=1, PLANE=2) : '

READ*,NSD

C

C Calculate the response matrix $B$.

C

CALL RESPONSE ( $B, A, X, Y, D E T N U M, P E, U N I T S, N S D, P P M C F)$

C

c

C

C

c
Set the background activity distribution $Z K L$ to a user chosen value $Z$ (choices 3 or 4 are recommended). T is the tota 1 number of counts.

$T=0.0$ 
DO $105 \mathrm{I}=1, \mathrm{M}$

$$
T=T+D(I)
$$

105 CONTINUE

$$
D A V G=T / M M
$$

C

PRINT*.' AVERAGE COUNT RATE $=$ ', DAVG

PRINT*, ' '

C

$S B=0.0$

DO $107 \mathrm{I}=1, \mathrm{MNXY}$

$$
S B=S B+B(I)
$$

107 CONTINUE

C

$Z A V G=T / S B$

$Z=Z A V G$

$D B K G=D A V G$

C

PRINT*, ' AVERAGE ACTIVITY (', UNITS, ' $)=$ ', ZAVG PRINT*, '

C

108 PRINT*,' COUNT RATE TO USE TO SET A BACKGROUND ACTIVITY? :

PRINT*, ' 0 - THE AVERAGE VALUE '

PRINT*,' 1 - THE MEDIAN VALUE '

PRINT*,' 2 - THE COUNT RATE FROM THE LOWEST MEASUREMENT

PRINT*,' 3 - THE WEIGHTED AVERAGE THAT MINIMIZES THE CHI SQUARE

PRINT*,' 4 - A USER DETERMINED COUNT RATE :

READ*, IG

IF (IG .EQ. 1) THEN

DO $109 \mathrm{I}=1, \mathrm{M}$

$$
\operatorname{DSORT}(\mathrm{I})=D(\mathrm{I})
$$

109 CONTINUE

CALL HPSORT(M.DSORT)

$K=F L O O R(M M / 2.0)$

$D B K G=D S O R T(K)$

$Z=D B K G *(Z A V G / D A V G)$

ELSE IF (IG .EQ. 2) THEN

DO $110 \quad I=1, M$

$$
\operatorname{DSORT}(I)=D(I)
$$

110 CONTINUE 


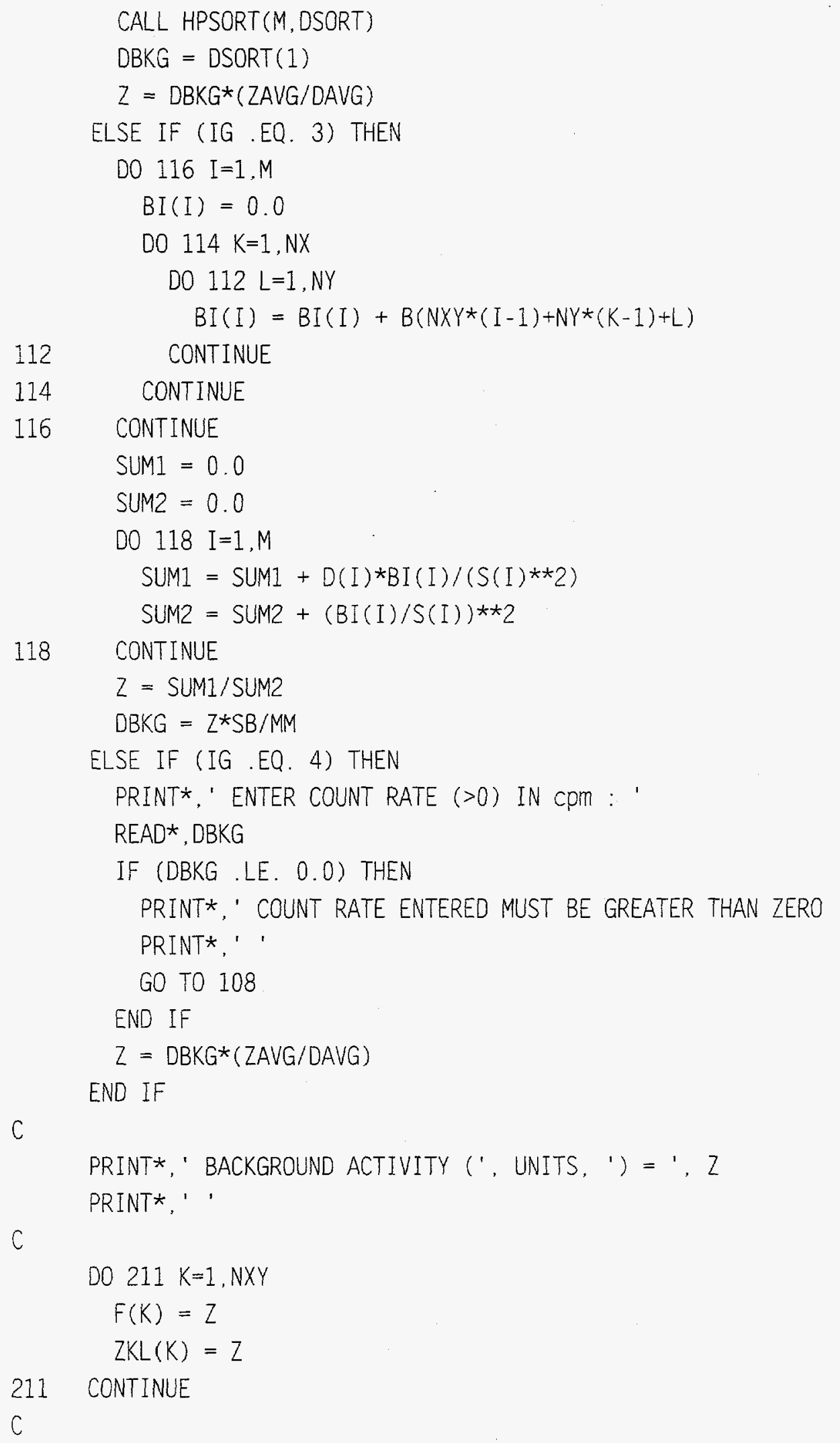


C Calculate the $\mathrm{CZ}$, the chi square of the background distribution.

C

$\mathrm{C} 1=0.0$

D0 $216 I=1, M$

$E Z(I)=0.0$

DO $214 \mathrm{~K}=1, \mathrm{NX}$

DO $212 L=1$, NY

$E Z(I)=E Z(I)+B(N X Y *(I-1)+N Y *(K-1)+L) * F(N Y *(K-1)+L)$

212 CONTINUE

214 CONTINUE

$C 1=C 1+((D(I)-E Z(I)) * * 2) /(S(I) * * 2)$

216 CONTINUE

c

$C Z=C 1$

C

PRINT*,' CHI SQUARE/INITIAL GUESS = ',CI

PRINT* , ' '

C

C Initialize the lambdas to zero

C

DO $218 \mathrm{I}=1, \mathrm{M}$

$\operatorname{LAMBDA}(\mathrm{I})=0.0$

218 CONTINUE

C

NUM $=0$

CALL MAXENT(LAMBDA, F, ZKL, D, E, S, B, CME, NUM)

C

C Save the lambdas from the MaxEnt deconvolution.

$\mathrm{C}$

DO $220 I=1, M$

$\operatorname{LME}(I)=\operatorname{LAMBDA}(I)$

220 CONTINUE

C

C The FMAP is equal to the background level.

C FMAP wi11 be used to construct a map with a composite of elevated areas $C$ placed on top of a map with background activity $Z$.

c

DO $224 K=1, N X Y$

$\operatorname{FMAP}(K)=Z$ 


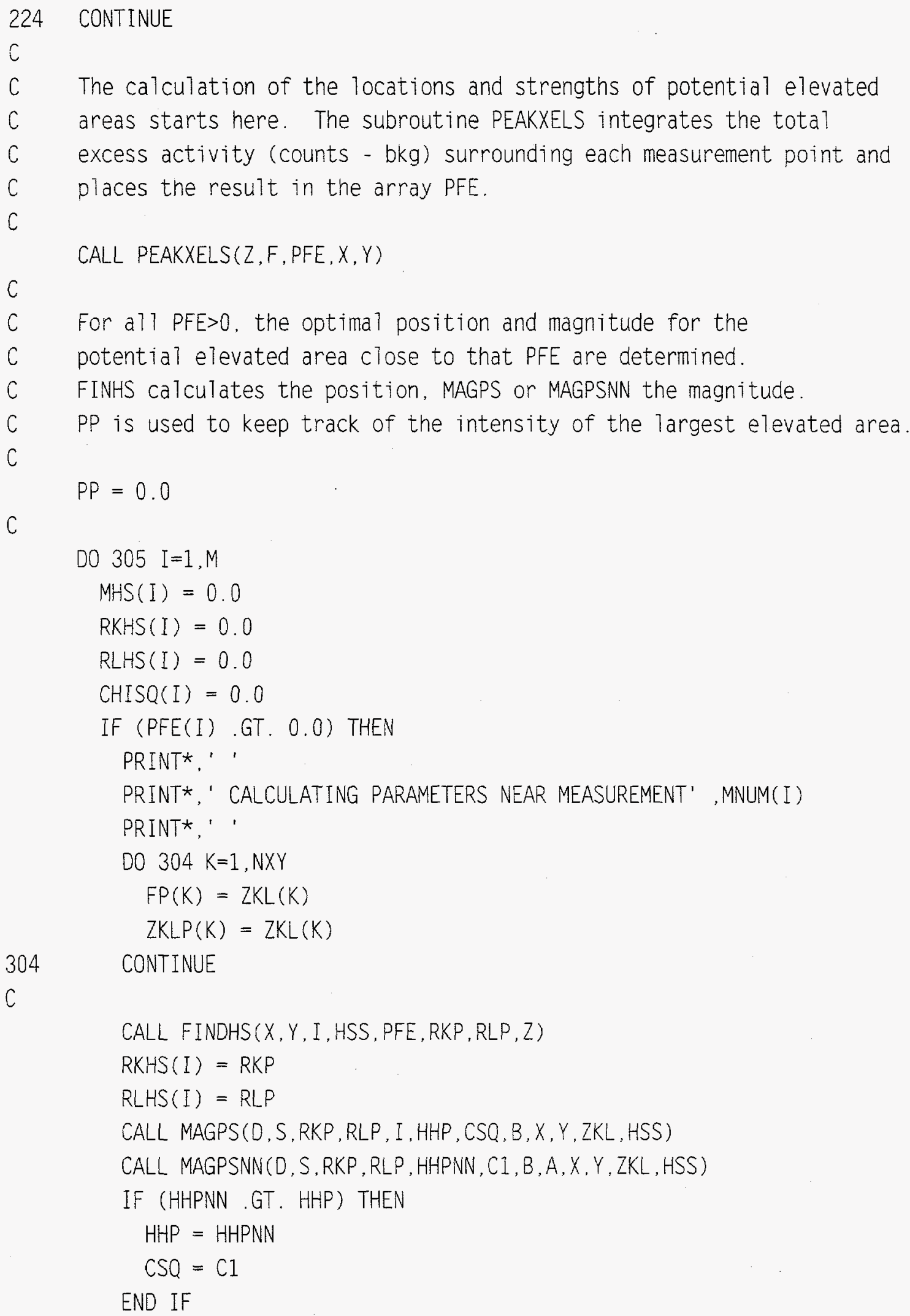


IF (HHP .LT. 1.0) THEN

$H H P=1.0$

END IF

C

C The elevated area is added to the FP and to the ZKLP (which were

$C$ set equal to the background activity). These will be used in a final

c MaxEnt deconvolution with background + elevated area.

C

CALL MAKEHS (RKP, RLP,FP, HHP, X, Y, HSS)

CALL MAKEHS (RKP, RLP, ZKLP, HHP, X, Y, HSS)

C

C A MaxEnt deconvolution of the FP using as default distribution the ZKLP.

C

C Initialize the lambdas - set them equal to the LME.

C

318

DO 318 III $=1, M$

$\operatorname{LAMBDA}($ III $)=\operatorname{LME}($ III)

C

CONTINUE

$N U M=1$

CALL MAXENT(LAMBDA,FP, ZKLP,D,E, S, B, C,NUM)

C

C The final magnitude of the elevated area is calculated.

c

$$
\begin{aligned}
& \mathrm{G1}=\mathrm{FLOOR}(0.5 * \mathrm{HSS}) \\
& G 2=\operatorname{CEILING}(0.5 * H S S) \\
& R K=N I N T(R K P) \\
& R L=N I N T(R L P) \\
& \mathrm{KL}=\mathrm{RK}-\mathrm{G1} \\
& K U=R K+G 1 \\
& \mathrm{LL}=\mathrm{RL}-\mathrm{G} 1 \\
& L U=R L+G 1 \\
& \text { IF (G1 .EQ. G2) THEN } \\
& R K=F L O O R(R K P) \\
& \mathrm{RL}=\mathrm{FLOOR}(\mathrm{RLP}) \\
& K L=R K-(G 1-1) \\
& K U=R K+G 1 \\
& L L=R L-(G 1-1) \\
& L U=R L+G 1
\end{aligned}
$$


END IF

C

$$
H H P=0.0
$$

DO $332 \mathrm{~K}=\mathrm{KL}, \mathrm{KU}$

D0 330 L=LL, LU

$H H P=H H P+F P(N Y *(K-1)+L) /(Z * H S S * H S S)$

330

332

CONTINUE

CONTINUE

C

$\operatorname{CSQ}=\mathrm{C}$

$\operatorname{MHS}(I)=H H P$

CHISQ(I) $=$ CSQ

C

C Print to screen the parameters of this potential ELEVATED AREA.

C

PRINT*, ' '

PRINT*,' ELEVATED AREA (?)/MEAS. NUMBER $=$ ',MNUM(I)

PRINT*, ' ELEVATED AREA (?)/X COORDINATE $=$ ', RKP

PRINT*, ' ELEVATED AREA (?)/Y COORDINATE $='$, RLP

PRINT*,' ELEVATED AREA (?)/SIZE ( $x$ BKG) = ', HHP

PRINT*,' ELEVATED AREA (?)/CHI SQUARE = ', CSQ

PRINT*, ' '

C

CALL MAKEHSMAP(RKP, RLP, FMAP, HHP , X, Y, HSS , Z)

C

C If this elevated area is the largest one so far, the FP are saved as

$C$ FPF, and IHP is set to I. The E are saved as as EF.

c

340

IF (MHS(I) .GT. PP) THEN

$\mathrm{IHP}=\mathrm{I}$

DO 340 II $=1, M$

$E F(I I)=E(I I)$

CONTINUE

DO $344 K=1, N X Y$

$$
F P F(K)=F P(K)
$$

344

CONTINUE

$$
P P=M H S(I)
$$

END IF

C 
END IF

305 CONTINUE

C

C Print to screen the parameters of the largest potential elevated

C area found.

C

RKP $=$ RKHS (IHP)

$R L P=R L H S(I H P)$

$H H P=M H S(I H P)$

$\mathrm{C} 1=\mathrm{CHISQ}(\mathrm{IHP})$

C

PRINT* : '

PRINT*,' PARAMETERS OF LARGEST POTENTIAL ElEVATED AREA FOUND: '

PRINT*,

PRINT*, 'MEAS. NUMBER $='$, MNUM(IHP)

PRINT*,,$\times$ COORDINATE $='$, RKP

PRINT*, $\quad Y$ COORDINATE $={ }^{\prime}$, RLP

PRINT*, $\operatorname{SIZE}(X B K G)=', H H P$

PRINT*, ' CHI SQUARE $=', C 1$

PRINT*, '

C

$C$ Set the FP equal to the FPF.

C

DO $432 K=1, N X Y$

$$
F P(K)=F P F(K)
$$

432 CONTINUE

C

c

C $\quad * * *$ OUTPUT $* * *$

c

D0 $905 I=1, M$

$\operatorname{ERR}(I)=(\operatorname{EF}(\mathrm{I})-D(I)) / S(I)$

905 CONTINUE

C

$\mathrm{CH}=\mathrm{EH} / /^{\prime} \cdot \mathrm{MXE} \mathrm{E}^{\prime}$

$\mathrm{TH}=\mathrm{EH} / /^{\prime} \cdot \mathrm{TBL} \cdot$

$W H=E H / / /^{\prime} \cdot A L L$

C

OPEN $(10, F I L E=C H . \quad$ STATUS $=$ 'NEW' $)$ 


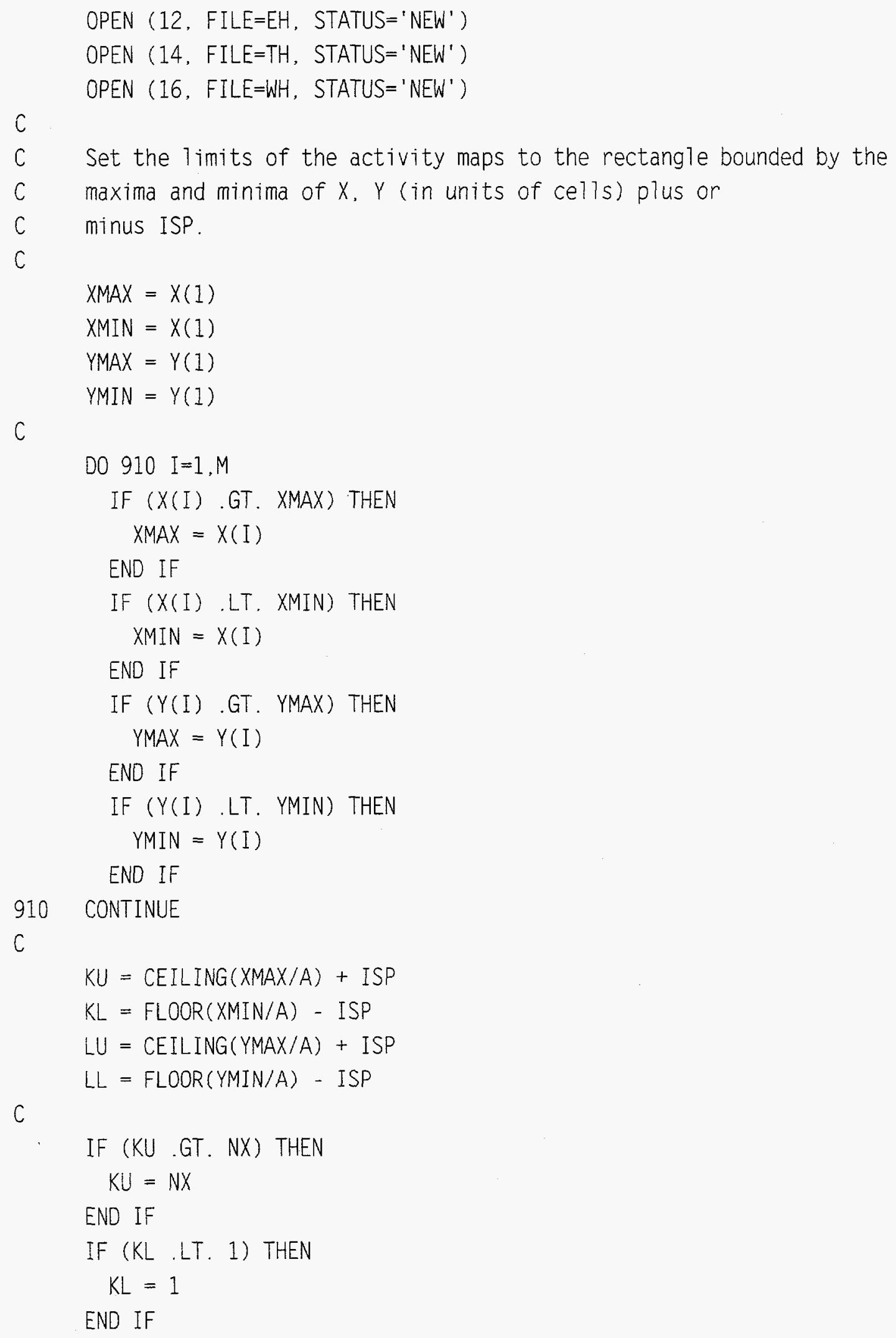




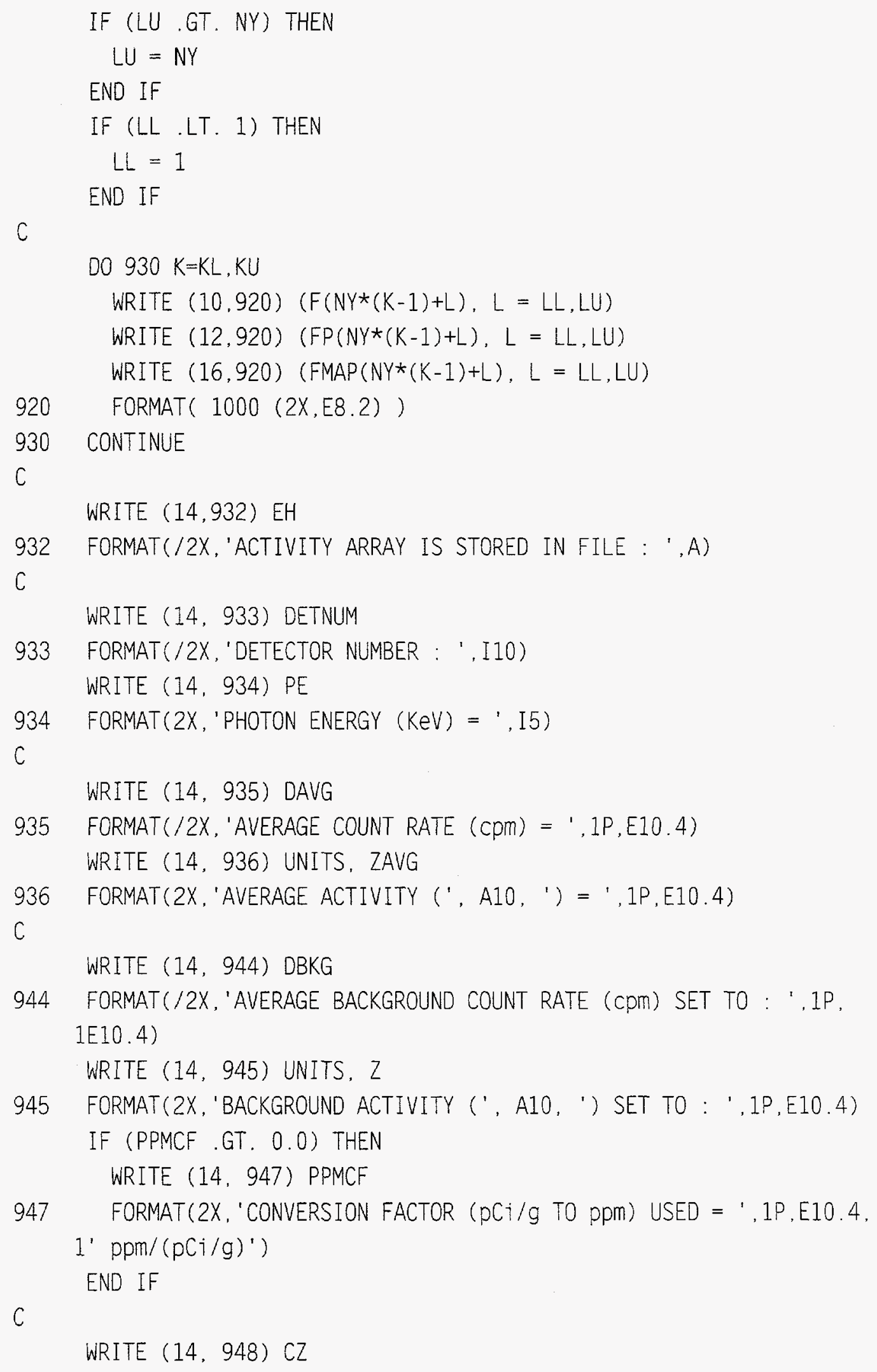


948 FORMAT(/2X, 'CHI SQUARE / BACKGROUND ACTIVITY = ', 1P,E10.4)

WRITE (14, 949) CME

949 FORMAT(2X, 'CHI SQUARE / MAXIMUM ENTROPY SOLUTION = ',F10.4)

C

WRITE (14, 950) IHP

950 FORMAT (/2X, 'LARGEST POTENTIAL ELEVATED AREA NEAR MEASUREMENT

1, I3)

WRITE (14, 951) HSA

951 FORMAT (2X, 'AREA $\left.\left(m^{\wedge} 2\right)=', F 10.4\right)$

WRITE (14, 952) C1

952 FORMAT $\left(2 X,{ }^{\prime}\right.$ CHI SQUARE $\left.=', F 10.4\right)$

WRITE $(14,954)$ HHP

954 FORMAT (2X, 'MAGNITUDE (X BACKGROUND $)=', F 10.4)$

$E A M=H H P * Z$

WRITE (14, 955) UNITS, EAM

955 FORMAT (2X, 'MAGNITUDE (', A10, ') $=$ ', 1P, E10.4)

C

WRITE (14, 956)

956 FORMAT $\left(/ / 2 X,{ }^{\prime}\right.$ NUM/MEAS CTS/MEAS CTS/CALC $\left.(E-D) / S='\right)$

D0 $960 \mathrm{I}=1, \mathrm{M}$

WRITE (14, 958) MNUM(I),D(I),EF(I),ERR(I)

958 FORMAT (2X,I8,2X,1P,E8 $2,2 X, E 8,2,2 X, 0 P, F 8,3)$

960 CONTINUE

C

WRITE $(14,970)$

970 FORMAT (/2X, 'NUM/MEAS X/HSPT Y/HSPT MAG HSPT CHI SQR')

C

D0 $985 I=1, M$

WRITE (14, 980) I,RKHS(I),RLHS(I),MHS (I),CHISQ(I)

980 FORMAT $(2 X, 18,2 X, F 8.2,2 X, F 8.2,2 X, F 8.1,2 X, F 8.2)$

985 CONTINUE

C

CLOSE (10, STATUS='KEEP')

CLOSE (12, STATUS $={ }^{\prime K E E P ')}$

CLOSE (14, STATUS='KEEP')

CLOSE (16, STATUS='KEEP')

C

PRINT*,'

PRINT*,' Activity Array is Stored in File: ',EH 
END

$\mathrm{C}$

$\mathrm{C}$

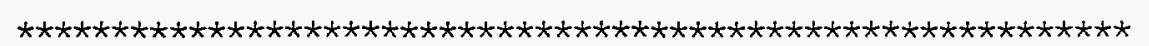

C

SUBROUTINE PEAKXELS(Z,F,PFE, X,Y)

C

INTEGER M,NX, NY, NXY, I, K, L, KL, KU, LL, LU, MHD, MHDSO, RR

INTEGER ISP

REAL $X X, Y Y, Z$

REAL A

REAL $F(N X Y)$, PFE (M)

REAL X(M), Y(M)

COMMON/AISP/A, ISP

COMMON/MN/M, NX, NY, MNXY, NXY

C

$$
\begin{aligned}
D 020 I & =1, M \\
M H D & =I S P \\
M H D S Q & =M H D * * 2 \\
X X & =X(I) / A \\
Y Y & =Y(I) / A \\
K L & =\operatorname{INT}(X X)-M H D \\
K U & =\operatorname{INT}(X X)+M H D \\
L L & =\operatorname{INT}(Y Y)-M H D \\
L U & =\operatorname{INT}(Y Y)+M H D
\end{aligned}
$$

C

IF (KL .LT. 1) THEN

$$
\mathrm{KL}=1
$$

END IF

IF (KU .GT. NX) THEN

$$
K U=N X
$$

END IF

IF (LL . LT. 1) THEN

$L L=1$

END IF

IF (LU .GT. NY) THEN

$$
L U=N Y
$$

END IF 
C

$\operatorname{PFE}(I)=0.0$

DO $10 \mathrm{~K}=\mathrm{KL}, \mathrm{KU}$

DO $8 \mathrm{~L}=L L, L U$

$R R=((\operatorname{INT}(X X)-K) * * 2)+((\operatorname{INT}(Y Y)-L) * * 2)$

IF (RR . LE. MHDSQ) THEN

$\operatorname{PFE}(I)=\operatorname{PFE}(I)+F(N Y *(K-1)+L)-Z$

END IF

8

CONTINUE

10 CONTINUE

20 CONTINUE

c

RETURN

END

C

C

C

SUBROUTINE FINDHS ( $X, Y$, IHP, HSS, PFE, RKP , RLP , Z)

C

c FINDHS calculates the optimal coordinates (RKP.RLP) of the elevated

C area.

C

INTEGER M, NX, NY, NXY, MNXY, ISP, IHP, HSS, IHPK, IHPL, K

INTEGER I, J,KK, LL , KKL , KKU, LLL , LLU

REAL DSQ, R2, RR, KO, XH, YH

REAL A,EPSSOMIN, RKP, RLP, Z

REAL $X(M), X X(M), Y(M), Y Y(M), P F E(M), P P F E(M)$

REAL RRIJ(M,M),RRHI(M),PHS(NX,NY),EPS(M),EPSSQ(NX,NY)

COMMON/AISP/A. ISP

COMMON/MN/M, NX,NY, MNXY, NXY

C

C R2 is defined in such a way that for a square grid it includes

C the eight closest measurement points (DSQ is the square of the

$C$ distance from the center of the square to any of the corners;

C R2 is the square of $\left\{1.5^{*}\right.$ the distance to closest measurement $\}$ ).

C (For a triangular grid it includes the six closest measurements).

$\mathrm{C}$

DSQ $=2.0 *(2.0 * A * F L O A T($ ISP $)) * * 2$

$\mathrm{R} 2=1.125 * \mathrm{DSQ}$ 
$C$ Calculate $(X X, Y Y)$, the $X$ and $y$ coordinates for measurement points

$C$ with PFE $>0$. Evaluate $K$, the number of such measurement points.

$\mathrm{C}$

$K=0$

DO $10 I=1, M$

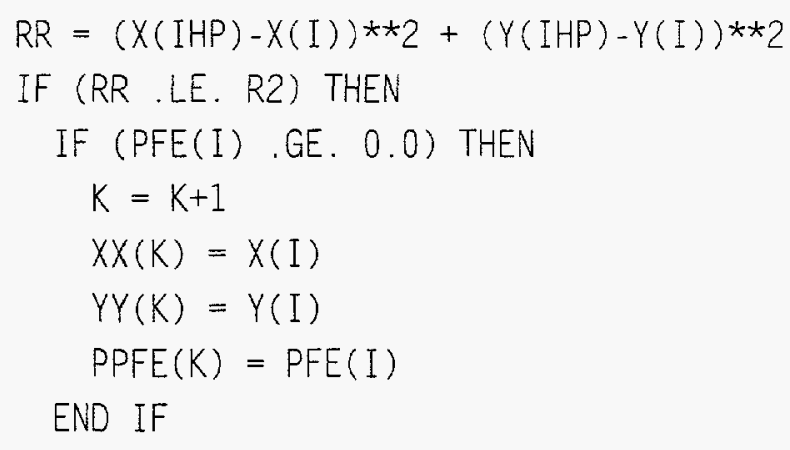

\section{END IF}

10 CONTINUE

$$
K O=F L O A T(K)
$$

C

C Calculate the square of the distance between detectors that are $100 \mathrm{~cm}$

$c$ above the ground and points on the ground directly under the

c detectors. Call it RRIJ(I,J).

C

12

DO $14 \mathrm{I}=1, \mathrm{~K}$

DO $12 J=1, K$

$$
\operatorname{RRIJ}(I, J)=(X X(I)-X X(J)) * * 2+(Y Y(I)-Y Y(J)) * * 2+10000.0
$$

CONTINUE

14 CONTINUE

c

IHPK $=\operatorname{NINT}(X($ IHP $) / A)$

$I H P L=N I N T(Y(I H P) / A)$

$K K L=I H P K-3 * I S P$

$K K U=I H P K+3 * I S P$

$L L L=I H P L-3 * I S P$

$L L U=I H P L+3 * I S P$

C

IF (KKL .LT. 1) THEN

$$
K K L=1
$$

END IF

IF (KKU .GT. NX) THEN 


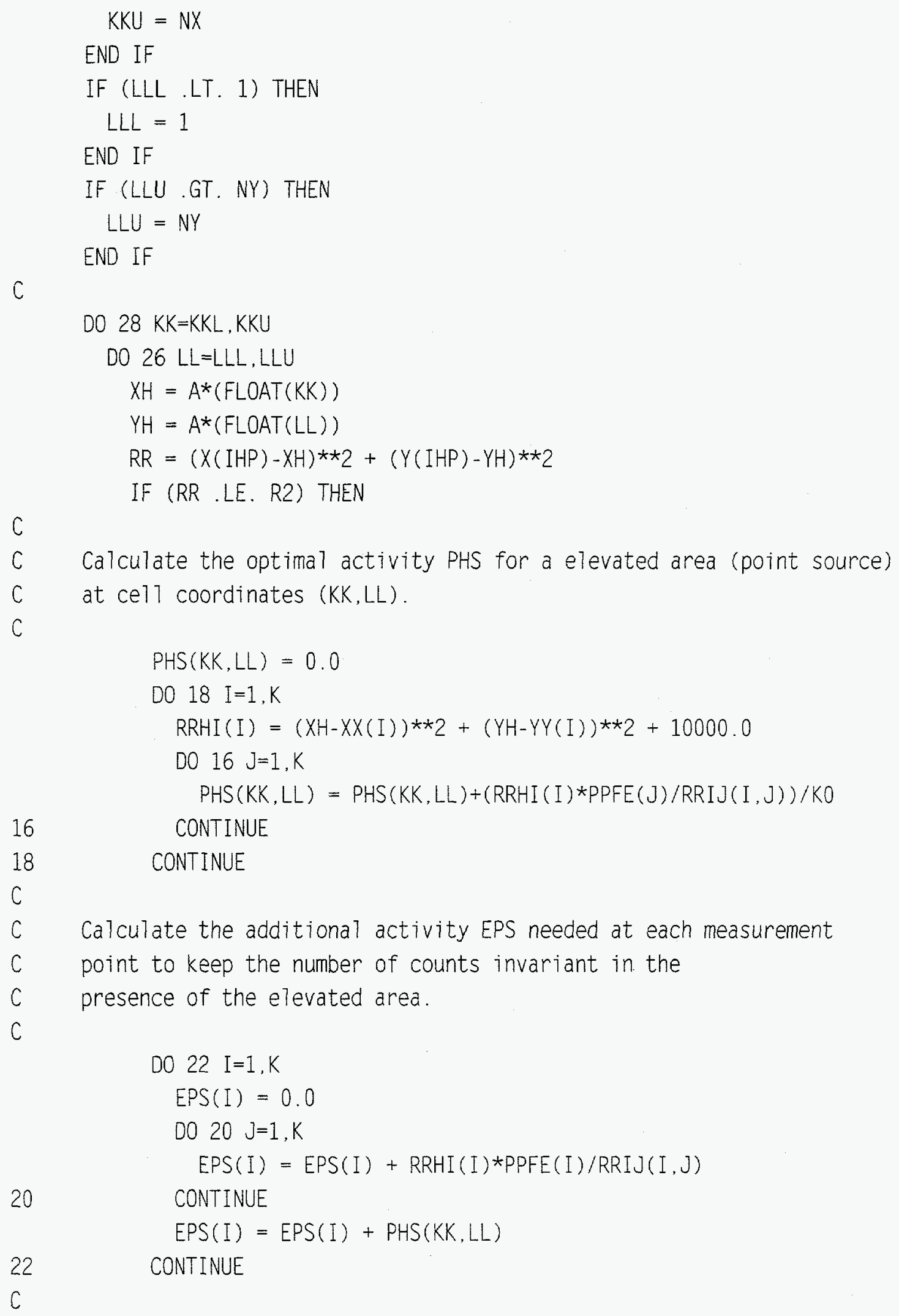


C Calculate EPSSQ(KK,LL), the sum of the square of the EPSS.

C

$\operatorname{EPSSQ}(K K, L L)=0.0$

DO $24 \mathrm{I}=1, \mathrm{~K}$

$\operatorname{EPSSQ}(K K, L L)=\operatorname{EPSSQ}(K K, L L)+(\operatorname{EPS}(I)) \star \star 2$

24

CONTINUE

C

END IF

26 CONTINUE

28 CONTINUE

C

C Place the elevated area at the cell coordinates (KK, LL) that

C minimize EPSSQ(KK, LL). Set (RKP, RLP) $=(X H / A, Y H / A)$.

c

EPSSQMIN $=$ EPSSQ $($ IHPK, IHPL $)$

DO $38 \mathrm{KK}=\mathrm{KKL}, \mathrm{KKU}$

DO $36 \mathrm{LL}=\mathrm{LLL}, \mathrm{LLU}$

$X H=A^{\star} F L O A T(K K)$

$Y H=A^{*} F L O A T(L L)$

$R R=(X(I H P)-X H) * * 2+(Y(I H P)-Y H) * * 2$

IF (RR .LE, R2) THEN

IF (EPSSQ(KK,LL) .LE. EPSSQMIN) THEN

EPSSOMIN $=E P S S Q(K K, L L)$

$R K P=X H / A$

$R L P=Y H / A$

END IF

END IF

36 CONTINUE

38 CONTINUE

C

RETURN

END

C

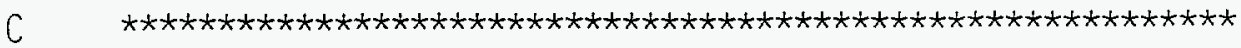

c

SUBROUTINE MAGPS(D, S, RKP , RLP, IHP, HHP , CSQ , B, X, Y , ZKL , HSS )

C

INTEGER M,NX, NY, NXY, MNXY, I , K, L, KP, LP, IHP

INTEGER ISP, HSS 
REAL DSQ, RR, R2, RKP, RLP, SUM1, SUM2, HHP, HPS, CSQ

REAL A

REAL $D(M), S(M), E(M), D E(M), F D(N X Y)$

REAL B(MNXY),X(M),Y(M)

REAL ZKL(NXY)

COMMON/AISP/A, ISP

COMMON/MN/M, NX, NY, MNXY, NXY

C

C MAGPS scales the point source at (RKP, RLP) to the optimal height,

$C$ which is given by the multiplicative factor HPS.

$C$ HPS is calculated by minimizing the chi square FOR THE

C MEASUREMENTS NEAR THE ELEVATED AREA under the assumption that the

C surface activity is given by the ZKL. with a point source

C added at (RKP, RLP).

C

C Set the $F D=Z K L$

C

DO $110 \quad K=1, N X Y$

$F D(K)=Z K L(K)$

110 CONTINUE

C

C Calculate the $\mathrm{E}$ due to the background.

C

DO $6 \mathrm{I}=1, \mathrm{M}$

$E(I)=0.0$

DO $4 \mathrm{~K}=1$, NX

DO $2 L=1$, NY

$E(I)=E(I)+B(N X Y *(I-1)+N Y *(K-1)+L) * F D(N Y *(K-1)+L)$

2

CONTINUE

CONTINUE

6 CONTINUE

C

C Calculate the DE due to activity at the point source

C

$K P=I N T(R K P)$

$L P=I N T(R L P)$

C

DO $10 I=1, M$

$D E(I)=B(N X Y *(I-1)+N Y *(K P-I)+L P) * F D(N Y *(K P-1)+L P)$ 
CONTINUE

c

C Calculate the optimal activity of the point source.

C

DSQ $=2.0 *(2.0 * A * F L O A T($ ISP $)) * \star 2$

$R 2=1.125 *$ DSQ

SUM1 $=0.0$

SUM2 $=0.0$

c

D0 $20 I=1, M$

$R R=(X(I H P)-X(I)) * * 2+(Y(I H P)-Y(I)) * * 2$

IF (RR. LE. R2) THEN

SUM1 $=$ SUMI $+D E(I) *(D(I)-E(I)) /(S(I) * * 2)$

SUM2 $=$ SUM2 $+D E(I) * D E(I) /(S(I) * * 2)$

END IF

20 CONTINUE

C

HPS $=1.0+$ SUM1/SUM2

C

C Add the elevated area to the FD.

C

$F D(N Y *(K P-1)+L P)=F D(N Y *(K P-1)+L P)+(H H P-1.0) * F D(N Y *(K P-1)+L P)$

C

C Calculate the chi square for this point source + background.

C

$\mathrm{CSQ}=0.0$

$0038 I=1, M$

$E(I)=0.0$

DO $37 K=1, N X$

DO $36 L=1, N Y$

$E(I)=E(I)+B(N X Y *(I-1)+N Y *(K-1)+L) * F D(N Y *(K-I)+L)$

36 CONTINUE

37 CONTINUE

$$
C S Q=C S Q+((D(I)-E(I)) \star * 2) /(S(I) \star * 2)
$$

38 CONTINUE

c

C Set HPP $=\mathrm{HPS} /($ area ELEVATED AREA in cells).

C

$H H P=H P S /(H S S * \star 2)$ 
C

RETURN

END

C

C

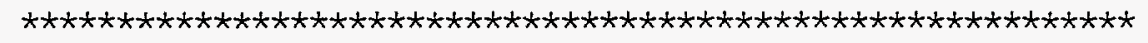

SUBROUTINE MAGPSNN(D, S, RKP , RLP, HHP , CSQ , B, A, X, Y, ZKL , HSS)

C

INTEGER M, NX, NY, NXY, MNXY I , K, L , RK, RL , NHS , HSS

REAL RR, RKP, RLP , HHP, HPS , CSQ , A

REAL $X X, Y Y, R R N, E B K G, D E$

REAL D(M),S(M),E(M),FD(NXY)

REAL $B(M N X Y), X(M), Y(M)$

REAL ZKL (NXY)

COMMON/MN/M, NX, NY, MNXY, NXY

C

C HHP is calculated by fitting the point source's magnitude to the

C total counts at the nearest's measurement point - under the

$C$ assumption that the surface activity is given by the $Z K L$

C with a point source added at (RKP, RLP).

C

C Set the FD $=Z K L$

C

DO $10 K=1$, NXY

$F D(K)=Z K L(K)$

10 CONTINUE

C

C Find the measurement point that is nearest to the elevated area. C

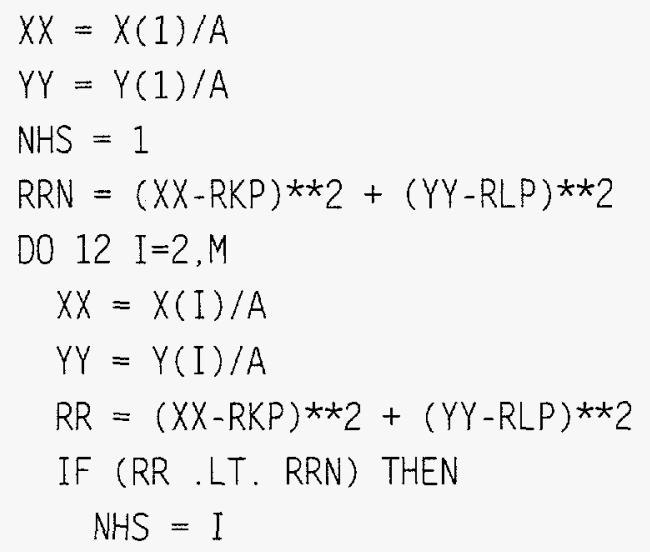




$$
\begin{aligned}
& \text { RRN }=\text { RR } \\
& \text { END IF }
\end{aligned}
$$

12 CONTINUE

C CaTculate the EBKG for the NHS due to the background.

C

$$
E B K G=0.0
$$

DO $24 K=1, N X$

$D 022 L=1, N Y$

$$
E B K G=E B K G+B(N X Y *(N H S-1)+N Y *(K-1)+L) * F D(N Y *(K-1)+L)
$$

CONTINUE

24

CONTINUE

C

C

C

$R K=\operatorname{INT}(R K P)$

$R L=I N T(R L P)$

C

$D E=D E+B(N X Y *(N H S-1)+N Y *(R K-1)+R L) * F D(N Y *(R K-1)+R L)$

$\mathrm{C}$

C Calculate the (7argest) optimal activity of the point source

C assuming $E(N H S)=E B K G+(H P S-1) * D E=D(N H S)+S(N H S)$.

C

$H P S=1.0+(D(N H S)+S(N H S)-E B K G) / D E$

C

C Add the point source to the $F D(K, L)$.

$\mathrm{C}$

$F D(N Y *(R K-1)+R L)=F D(N Y *(R K-1)+R L)+(H H P-1.0) * F D(N Y *(R K-1)+R L)$

C

c Calculate the chi square for this point source + background.

C

$C S Q=0.0$

DO $38 \mathrm{I}=1, \mathrm{M}$

$$
E(I)=0.0
$$

DO $37 K=1, N X$

$0036 \mathrm{~L}=1$, NY

$E(I)=E(I)+B(N X Y *(I-1)+N Y *(K-1)+L) * F D(N Y *(K-1)+L)$

36 CONTINUE

37 CONTINUE 


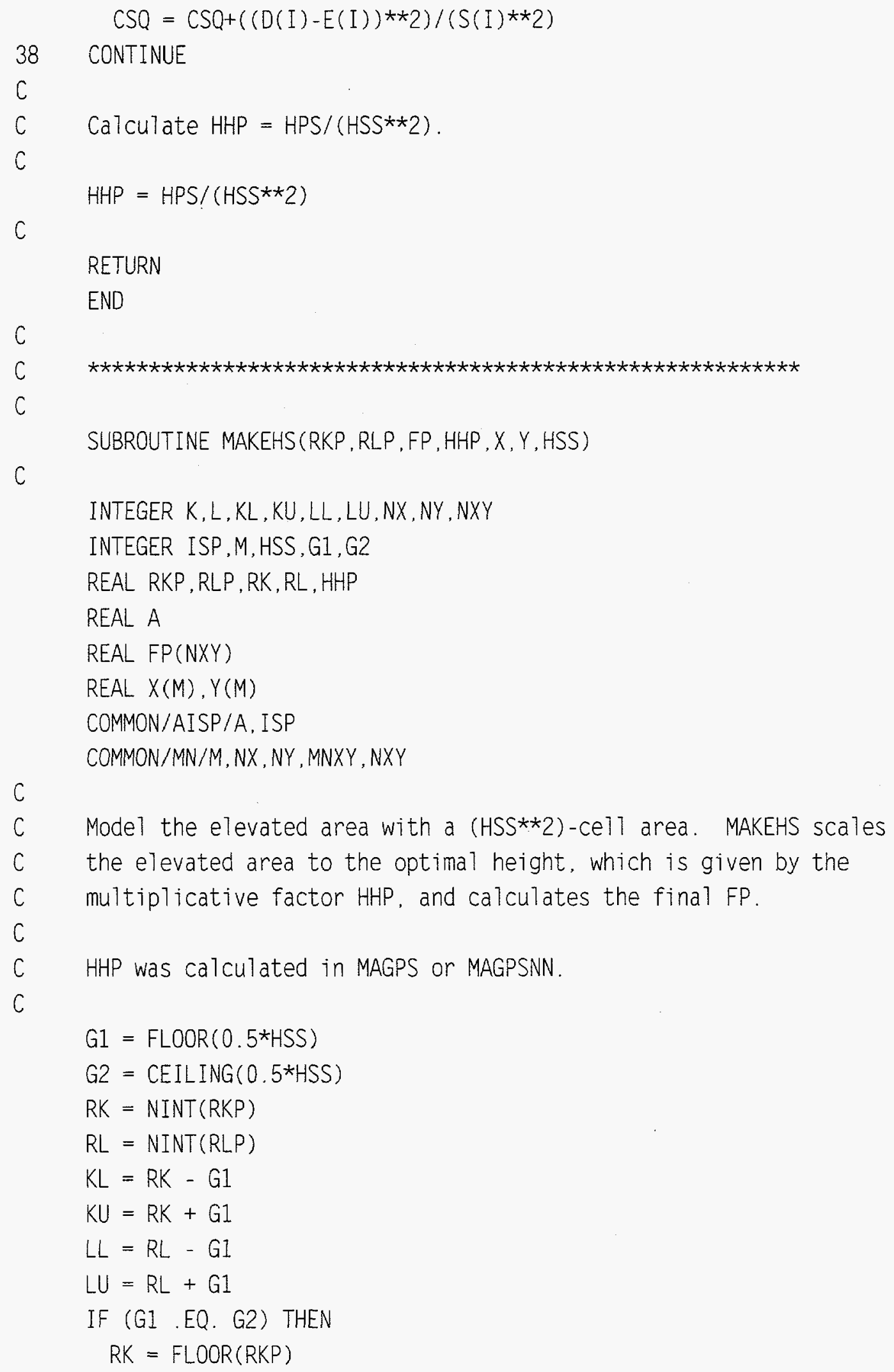




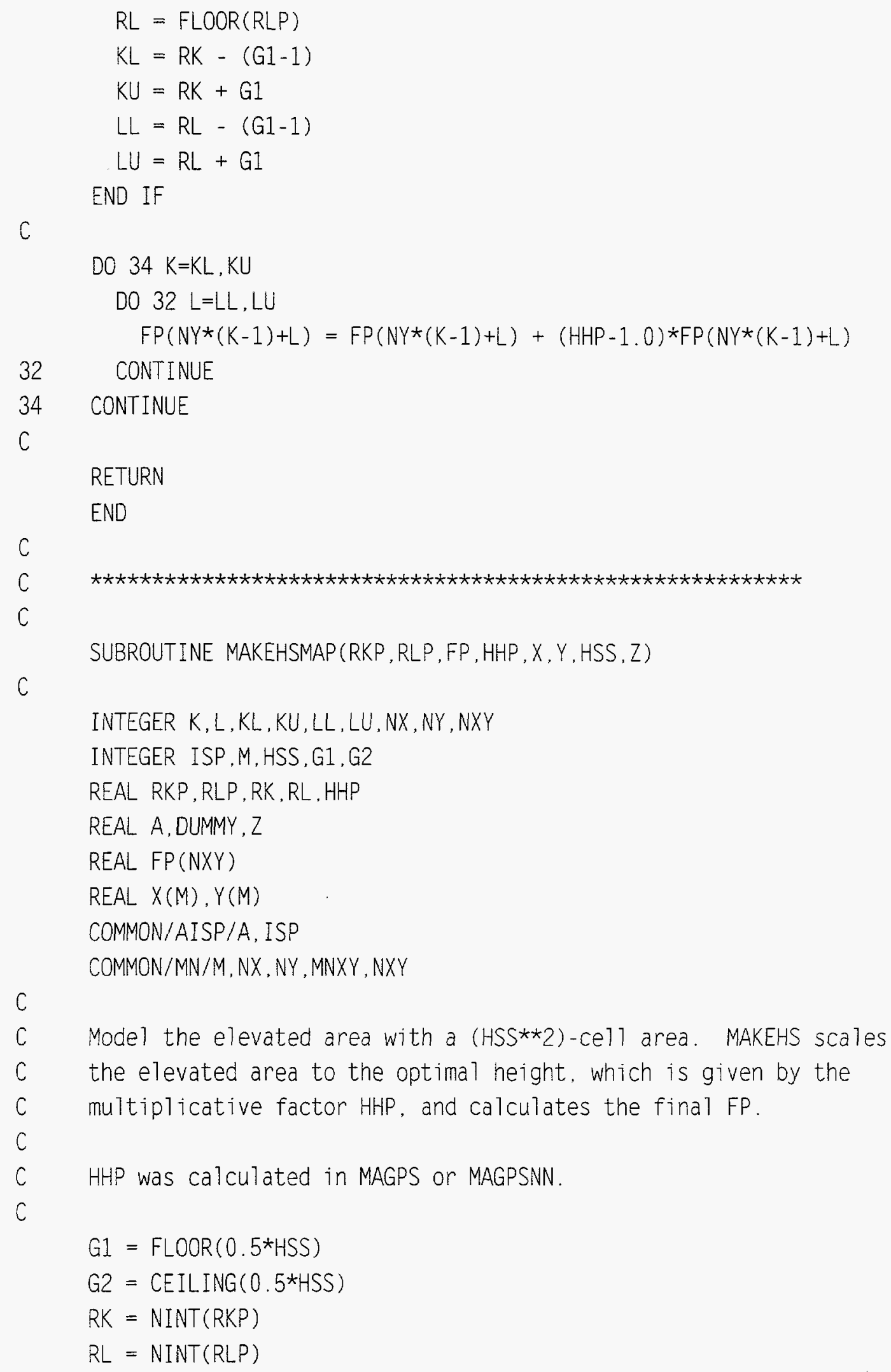




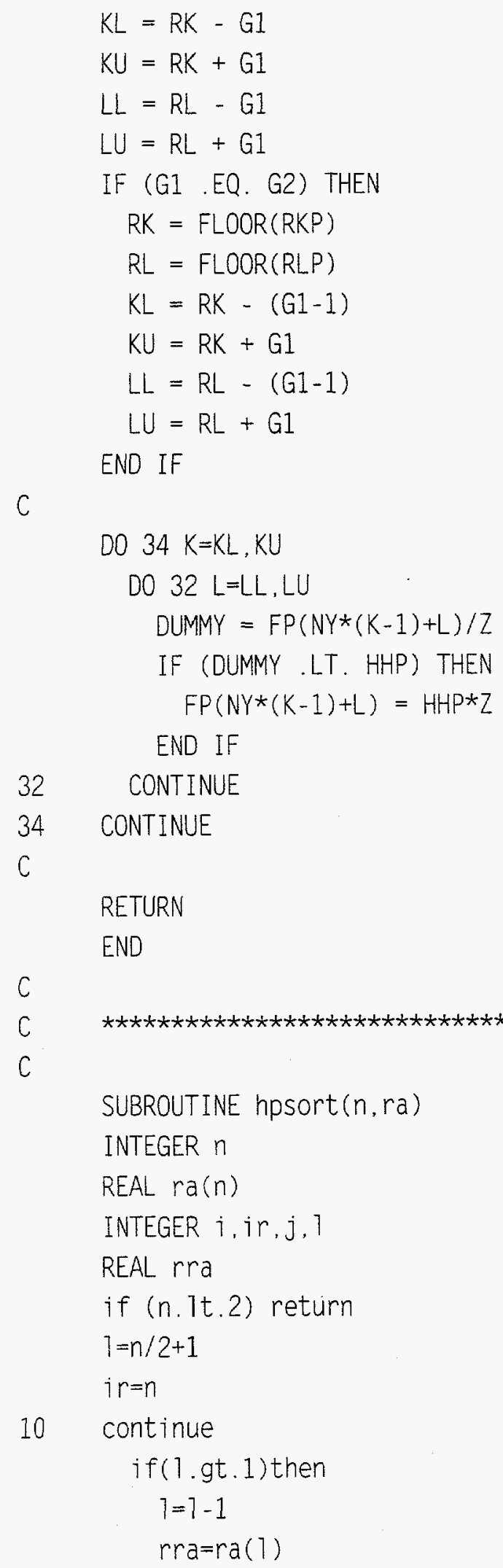




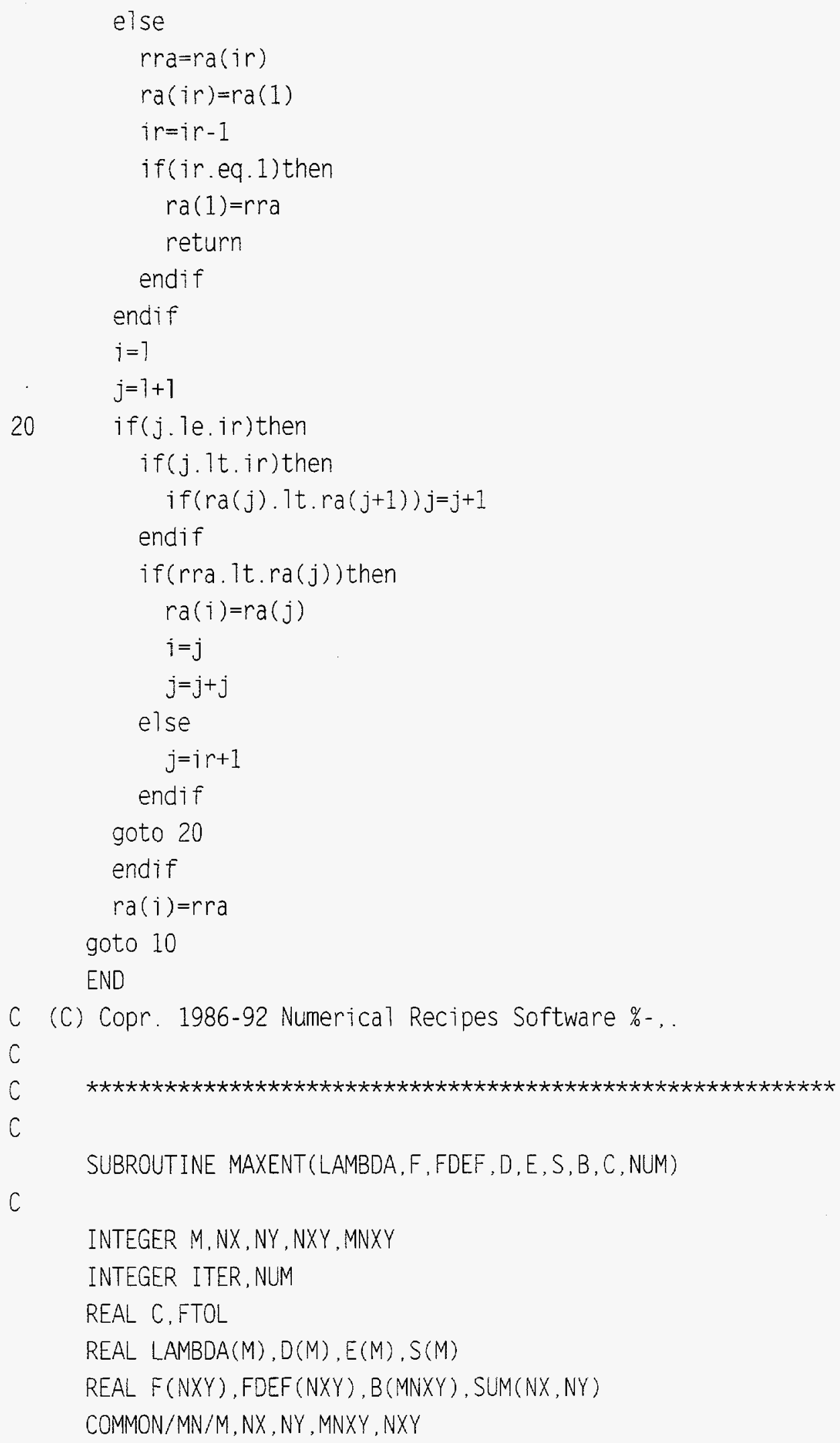




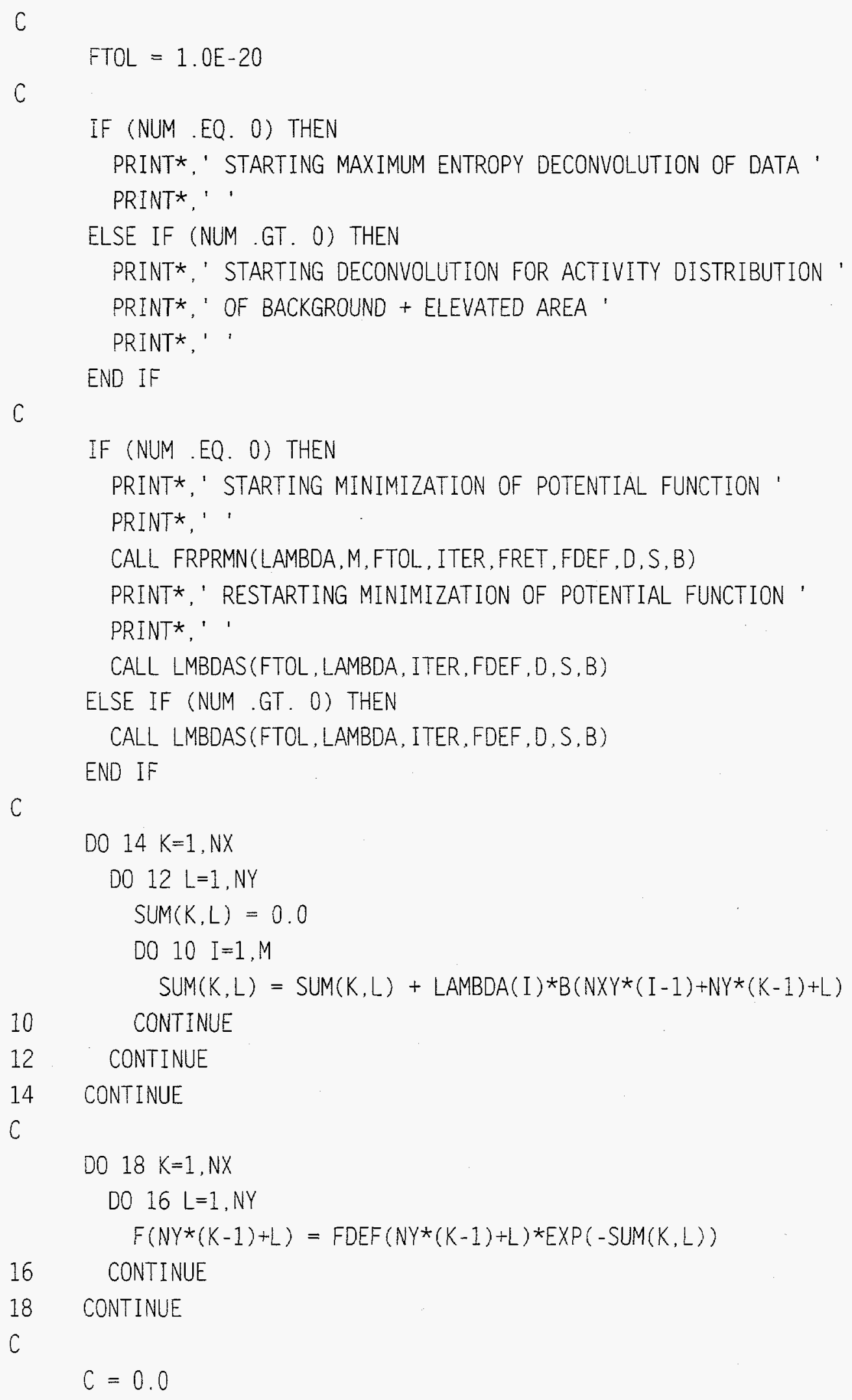




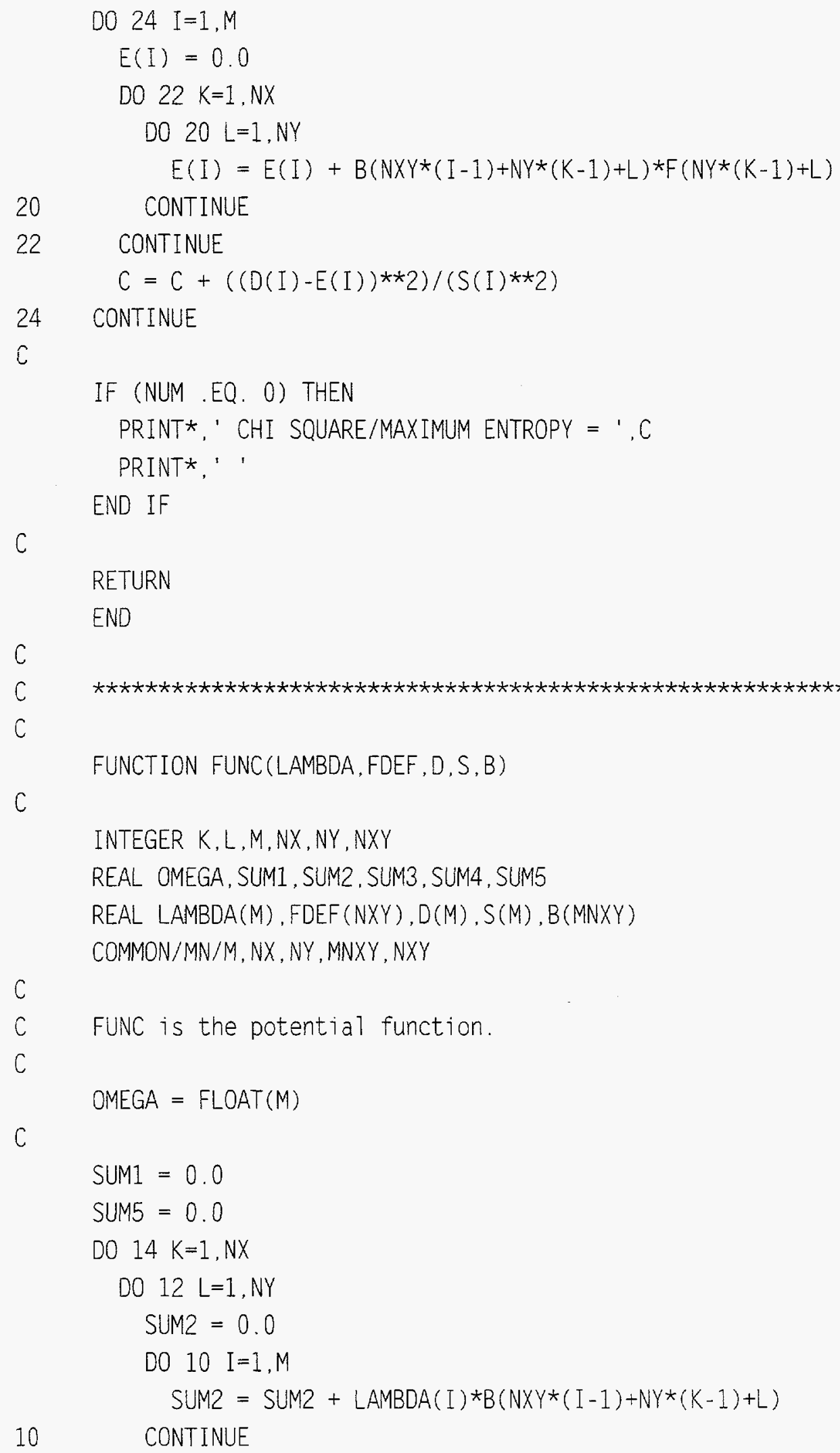




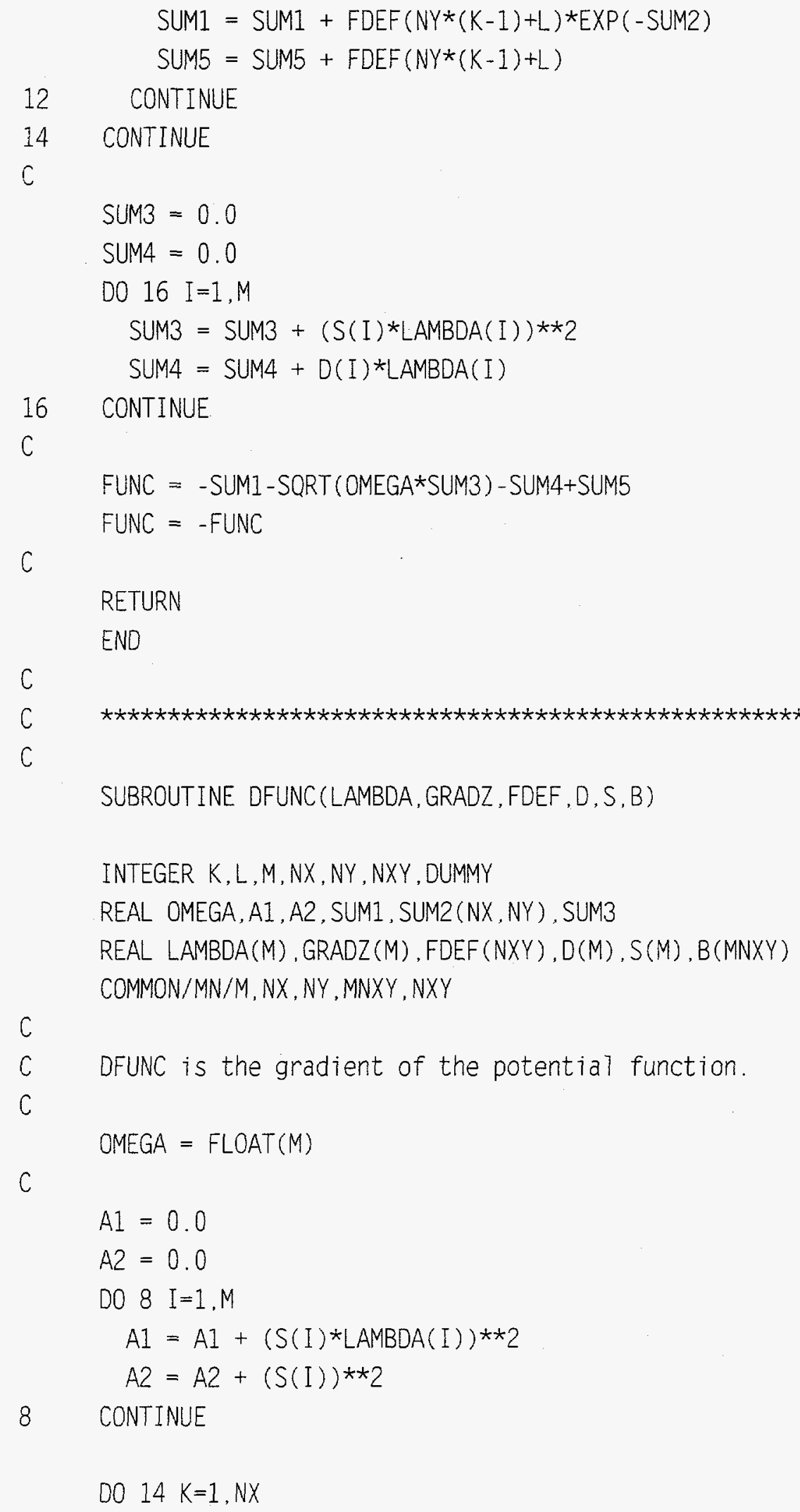

8 CONTINUE

DO $14 K=1$, NX 
DO $12 L=1$, NY

$\operatorname{SuM} 2(K, L)=0.0$

DO $10 \mathrm{I}=1, \mathrm{M}$

$\operatorname{SUM} 2(K, L)=\operatorname{SUM} 2(K, L)+\operatorname{LAMBDA}(I) * B(N X Y *(I-1)+N Y *(K-1)+L)$

10 CONTINUE

12 CONTINUE

14 CONTINUE

C

$0030 \quad i=1, M$

SUM1 $=0.0$

DO $18 K=1$, NX

DO $16 L=1, N Y$

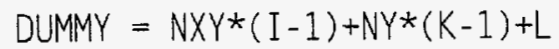

SUM1 $=$ SUM1 + FDEF $(N Y *(K-1)+L) * \operatorname{EXP}(-\operatorname{SUM} 2(K, L)) * B($ CUMMY $)$

16 CONTINUE

18 CONTINUE

C

SUM3 $=((S(I)) * * 2) *($ SQRT $(O M E G A / A 2))$

IF (AI .GT. 1.0E-20) THEN

SUM3 $=((S(I)) * * 2) * L A M B D A(I) *($ SQRT $($ OMEGA A A $))$

END IF

C

$$
\text { GRADZ (I) }=\text { SUMI }- \text { SUM3 }-D(I)
$$

GRADZ $(I)=-G R A D Z(I)$

30 CONTINUE

C

RETURN

END

C

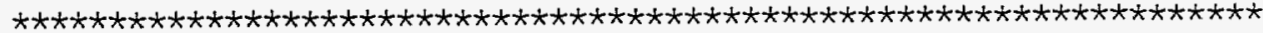

SUBROUTINE LMBDAS(FTOL, LAMBDA, ITER, FDEF, D.S, B)

INTEGER $K, L, M, N X, N Y, N X Y$, ITER, ITERMAX

REAL OMEGA, LB(NX,NY), EPS

REAL TWOMU, Z, ZOLD, FTOL, P,C

REAL LAMBDA(M), LAMBDAOLD(M), DL, DLMIN

REAL FDEF (NXY),D(M),E(M),S(M),B(MNXY)

COMMON/MN/M, NX, NY, MNXY, NXY 
C

OMEGA $=$ FLOAT $(M)$

ITER $=1$

ITERMAX $=250$

$E P S=1.0 E-10$

DLMIN $=0.1$

$P=0.01$

DO $2 I=1, M$

$\operatorname{LAMBDAOLD}(I)=\operatorname{LAMBDA}(I)$

2 CONTINUE

ZOLD $=$ FUNC (LAMBDA, FDEF $, D, S, B)$

C

$008 K=1$, NX

DO $6 \mathrm{~L}=1$, NY

$L B(K, L)=0.0$

DO $4 \mathrm{I}=1, \mathrm{M}$

$L B(K, L)=L B(K, L)+L A M B D A(I) * B(N X Y *(I-1)+N Y *(K-1)+L)$

4 CONTINUE

6 CONTINUE

8 CONTINUE

$C=0.0$

DO $14 I=1, M$

$E(I)=0.0$

DO $12 K=1$, NX

DO $10 L=1, N Y$

$E(I)=E(I)+F D E F(N Y *(K-1)+L) * E X P(-L B(K, L)) * B(N X Y *(I-1)+N Y *(K-1)+L)$

10

CONTINUE

12 CONTINUE

$$
C=C+((E(I)-D(I)) / S(I)) * * 2
$$

14 CONTINUE

C

C Use the integral equation to modify the lambdas.

c

15 TWOMU $=0.0$

DO $16 I=1, M$

TWOMU $=$ TWOMU $+(S(I) *$ LAMBDA $(I)) * * 2$

16 CONTINUE

TWOMU $=$ SQRT $($ TWOMU/OMEGA $)$

C 
DO $18 I=1, M$

$\operatorname{LAMBDA}(I)=(1.0-P) * \operatorname{LAMBDA}(I)+P *(E(I)-D(I)) *$ TWOMU $/(S(I) * * 2)$

18 CONTINUE

$Z=F U N C(L A M B D A, F D E F, D, S, B)$

C

IF (Z .GT. ZOLD) THEN

DO $24 \quad I=1, M$

$\operatorname{LAMBDA}(I)=\operatorname{LAMBDAOLD}(\mathrm{I})$

24 CONTINUE

IF (ABS (C-OMEGA) .LT. SQRT (OMEGA)) THEN

RETURN

END IF

CALL FRPRMN (LAMBDA, M, FTOL, ITER, FRET, FDEF, D , S , B)

RETURN

END IF

C

IF (ITER . GT. ITERMAX) THEN

DO $26 \mathrm{I}=1, \mathrm{M}$

$\operatorname{LAMBDA}(\mathrm{I})=\operatorname{LAMBDAOLD}(\mathrm{I})$

26 CONTINUE

IF (ABS (C-OMEGA) .LT. SQRT(OMEGA)) THEN

RETURN

END IF

CALL FRPRMN(LAMBDA, M, FTOL, ITER, FRET, FDEF, D , S, B)

RETURN

END IF

c

PRINT*', ' SUBROUTINE LMBDAS/NUMBER OF ITERATIONS: ', ITER

PRINT*,'

C

IF (2.0*ABS(Z-ZOLD) .LE. FTOL*(ABS(Z)+ABS (ZOLD)+EPS)) THEN RETURN

END IF

C

DO $34 K=1, N X$

DO $32 L=1, N Y$

$L B(K, L)=0.0$

DO $30 \quad I=1, M$

$$
L B(K, L)=L B(K, L)+\operatorname{LAMBDA}(I) * B(N X Y *(I-1)+N Y *(K-1)+L)
$$




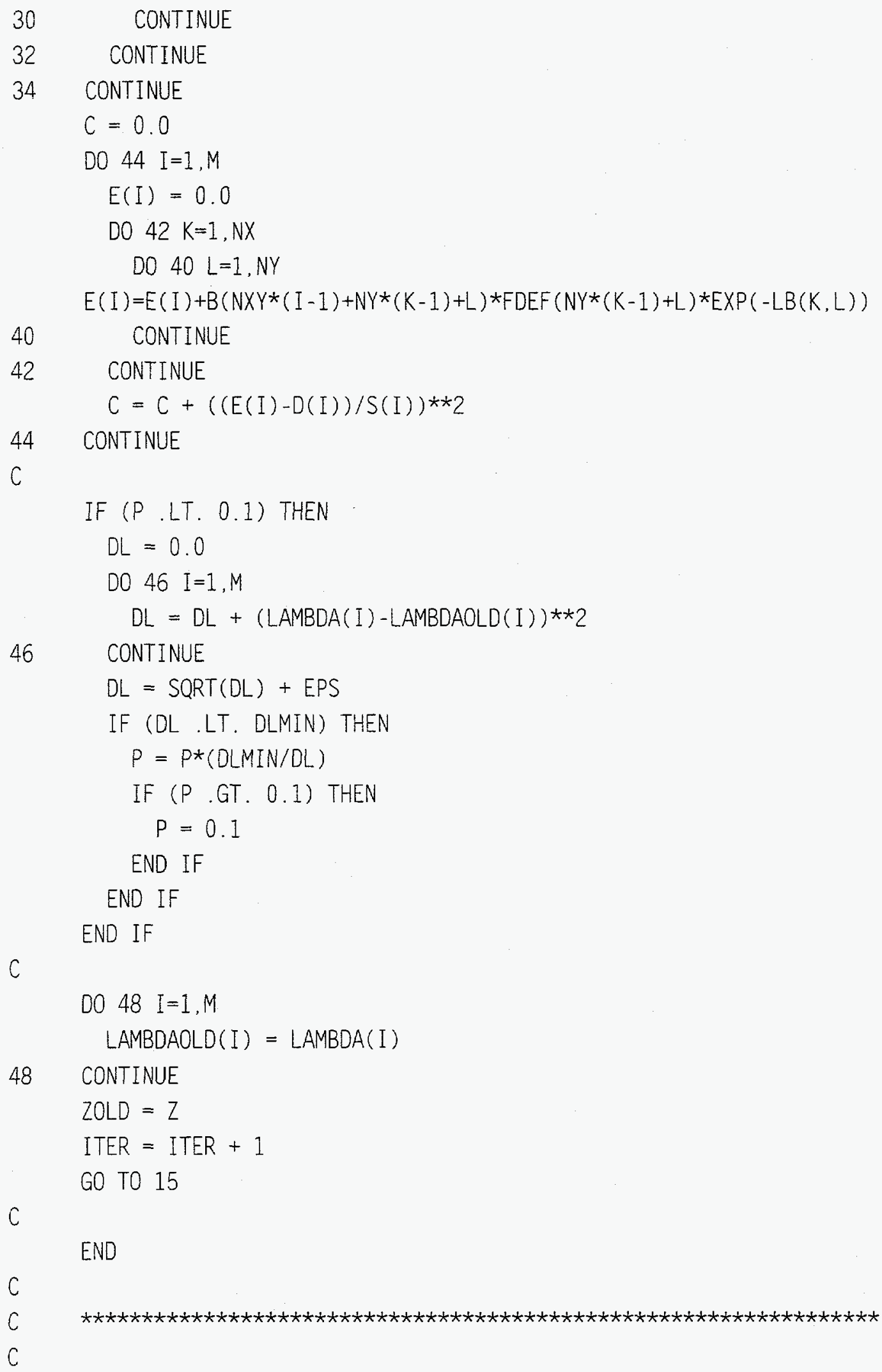


SUBROUTINE frprmn(p,n,ftol, iter, fret, FDEF, D, S.B)

INTEGER iter, $n$, NMAX, ITMAX

REAL fret, fto $1, p(n)$, EPS, func

EXTERNAL funC

PARAMETER $($ NMAX $=500$, ITMAX $=200, E P S=1, e-10)$

CU USES dfunc, func, 7 inmin

INTEGER its, $j$

REAL dgg, fp, gam, gg, g(NMAX), h(NMAX), xi (NMAX)

REAL FDEF $(*), D(*), S(*), B(*)$

$f p=\hat{\text { Tunc }}(p, F D E F, D, S, B)$

$c a 17 \operatorname{dfunc}(p, x i, F D E F, D, S, B)$

do $11 j=1, n$

$$
\begin{aligned}
& g(j)=-x i(j) \\
& h(j)=g(j) \\
& x i(j)=h(j)
\end{aligned}
$$

11 continue

do 14 its $=1$, ITMAX

$$
\text { iter }=i t s
$$

PRINT*,' SUBROUTINE FRPRMN/NUMBER OF ITERATIONS: ', ITER

PRINT*,

cal1 1 inmin $(p, x i, n$, fret, FDEF, D, S, B)

if $(2$. *abs (fret-fp). le . ftol*(abs (fret) +abs (fp)+EPS)) return

$f p=f u n c(p, F D E F, D, S, B)$

cal1 dfunc $(p, x i, F D E F, D, S, B)$

$g g=0$.

dgg $=0$

do $12 j=1, n$

$$
g g=g g+g(j) * * 2
$$

C $\quad \operatorname{dgg}=\operatorname{dgg}+x i(j) * * 2$

$$
d g g=d g g+(x i(j)+g(j)) * x i(j)
$$

12 continue

if (gg.eq.0.) return

gam=dgg $/ g g$

do $13 j=1, n$

$$
\begin{aligned}
& g(j)=-x i(j) \\
& h(j)=g(j)+g a m * h(j) \\
& x i(j)=h(j)
\end{aligned}
$$

13 continue

14 continue 
pause 'frprmn maximum iterations exceeded'

return

END

C (C) Copr. 1986-92 Numerical Recipes Software :-..

C

SUBROUTINE 7 inmin $(p, x i, n$, fret, FDEF, D, S , B)

INTEGER $n$, NMAX

REAL fret, $p(n), x i(n)$, TOL

PARAMETER $($ NMAX $=500, T O L=1, e-6)$

CU USES brent, f1dim, mnbrak

INTEGER $j$, ncom

REAL ax, bx, fa, fb,fx, xmin, xx, pcom(NMAX), xicom(NMAX), brent

REAL FDEF $(*), D(*), S(*), B(*)$

COMMON/ficom/pCOm, Xicom, ncom

EXTERNAL f1dim

ncom=n

do $11 j=1, n$

$$
\begin{aligned}
& \operatorname{pcom}(j)=p(j) \\
& x i \operatorname{com}(j)=x i(j)
\end{aligned}
$$

11 continue

$a x=0$.

$x x=1$.

cal1 mnbrak ( $a x, x x, b x, f a, f x, f b, f 1 d i m, F D E F, D, S, B)$

fret=brent $(a x, x x, b x, f 1 d i m, T O L, x \min , F D E F, D, S, B)$

do $12 j=1, n$

$$
\begin{aligned}
& x i(j)=x \min n x i(j) \\
& p(j)=p(j)+x i(j)
\end{aligned}
$$

12

continue

return

END

C (C) Copr. 1986-92 Numerical Recipes Software \%-,.

C

C

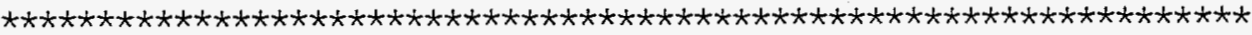

C

SUBROUT INE mnbrak ( $a x, b x, c x, f a, f b, f c$, func, FDEF, D, S, B)

REAL $a x, b x, c x, f a, f b, f c, f u n c, G O L D, G L I M I T$, TINY

EXTERNAL func 
PARAMETER (GOLD $=1.618034$, GLIMIT $=100$, TINY $=1 . e-20)$

REAL dum, fu, q, r, u, ul im

REAL FDEF $(*), D(*), S(*), B(*)$

$f a=f u n c(a x, F D E F, D, S, B)$

$f b=f$ unc $(b x, F D E F, D, S, B)$

if $(f b . g t . f a)$ then

dum=ax

$a x=b x$

$b x=d u m$

$d u m=f b$

$f b=f a$

$f a=d u m$

endif

$c x=b x+G O L D *(b x-a x)$

$f C=$ func $(c x, F D E F, D, S, B)$

$1 \quad i f(f b . g e . f c)$ then

$r=(b x-a x) *(f b-f c)$

$q=(b x-c x) *(f b-f a)$

$u=b x-((b x-c x) * q-(b x-a x) * r) /\left(2 \cdot{ }^{*} \operatorname{sign}(\max (a b s(q-r), T I N Y), q-r)\right)$

$u 7$ im $=b x+G L I M I T *(c x-b x)$

if $((b x-u) *(u-c x) \cdot g t \cdot 0$.$) then$

$f u=f u n c(U, F D E F, D, S, B)$

if $(f u .7 t$. fc) then

$a x=b x$

$f a=f b$

$b x=u$

$\mathrm{fb}=\mathrm{fu}$

return

else if(fu.gt.fb)then

$c x=u$

$\mathrm{fc}=\mathrm{fu}$

return

endif

$u=c x+G O L D *(c x-b x)$

$f u=f u n c(u, F D E F, D, S, B)$

else if $\left((c x-u)^{*}(u-u\rceil i m\right)$.gt. 0. ) then

fu=func $(U, F D E F, D, S, B)$

if $(f u .7 t . f c)$ then

$b x=c x$ 


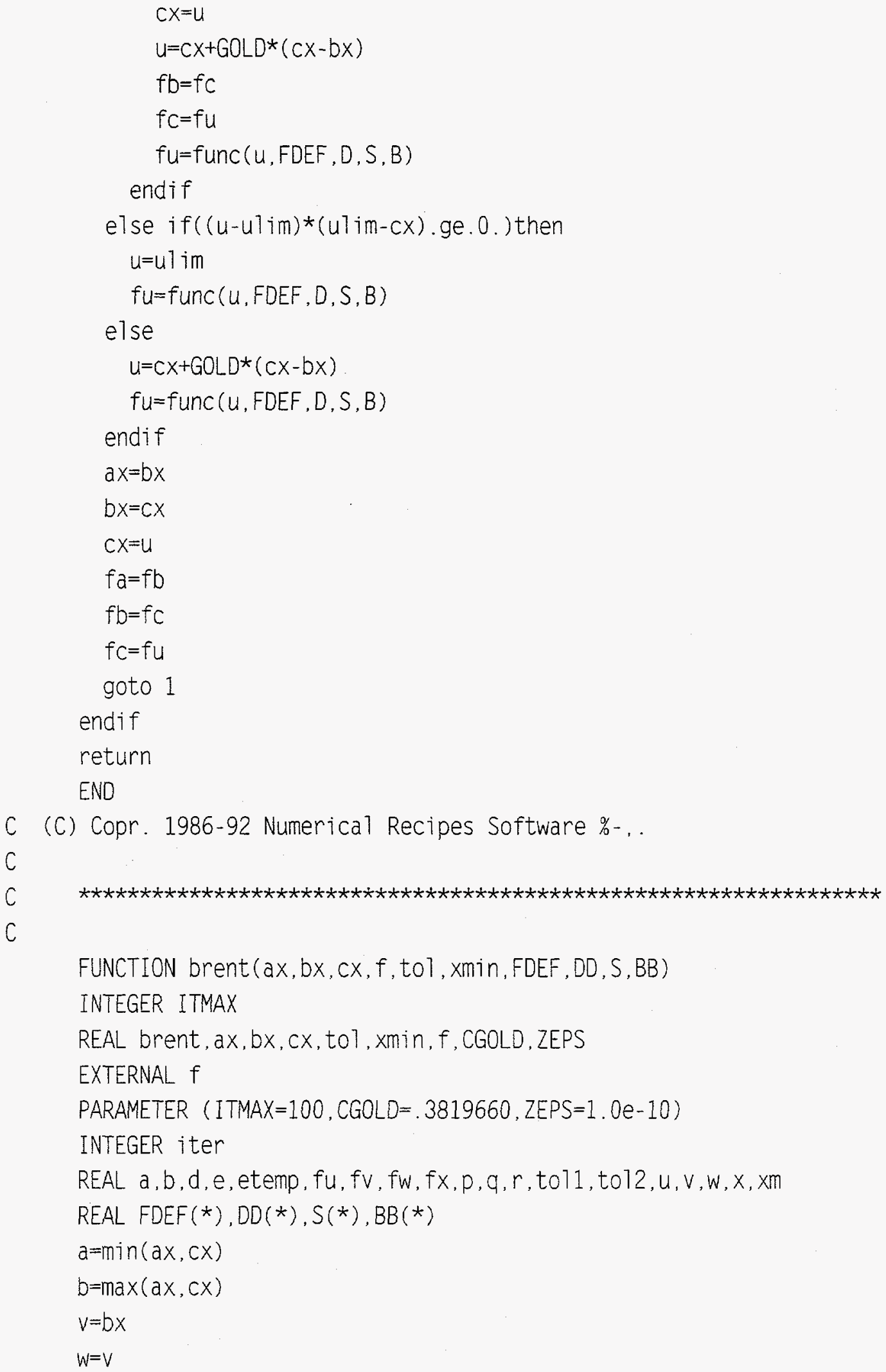




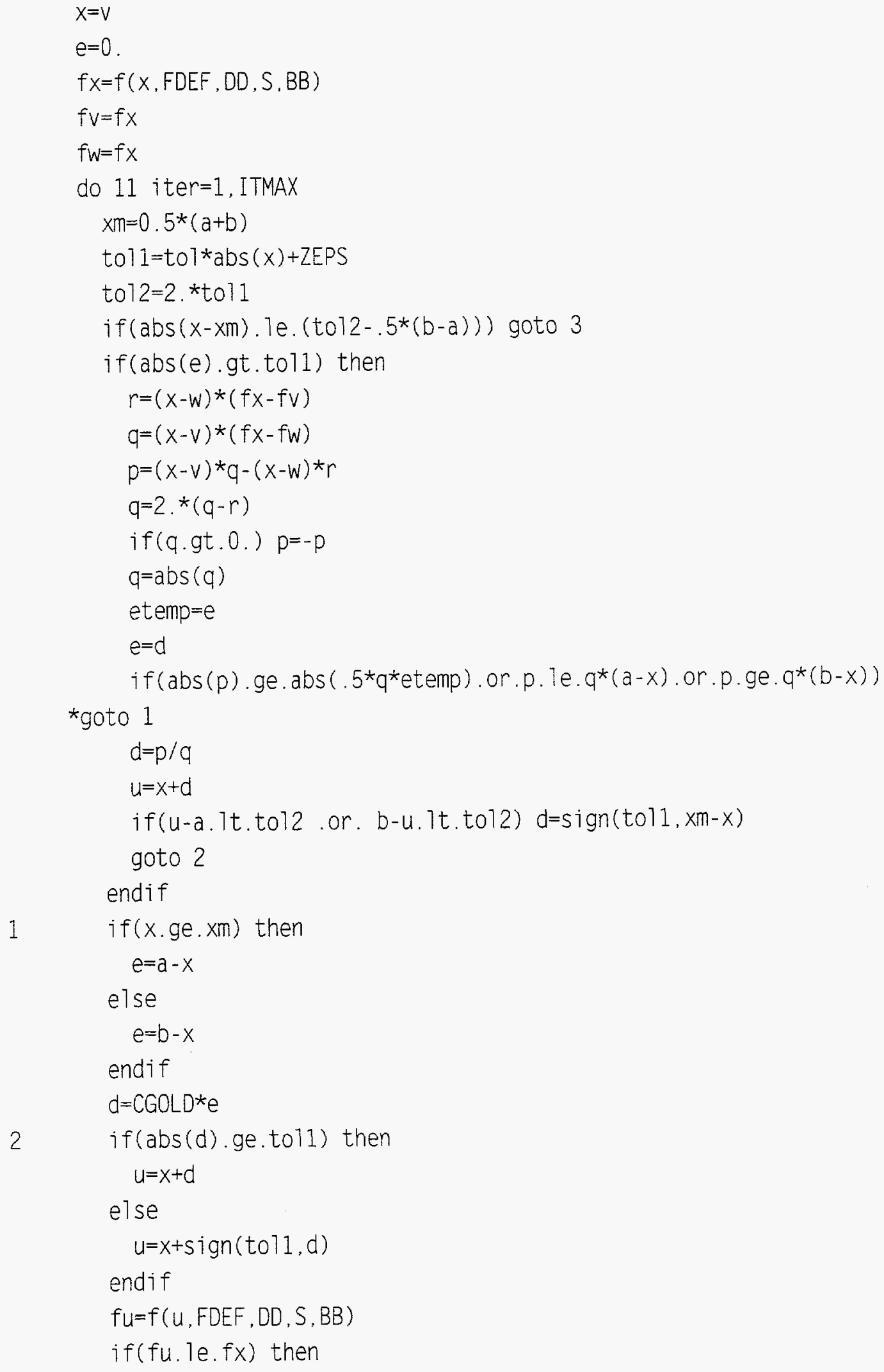




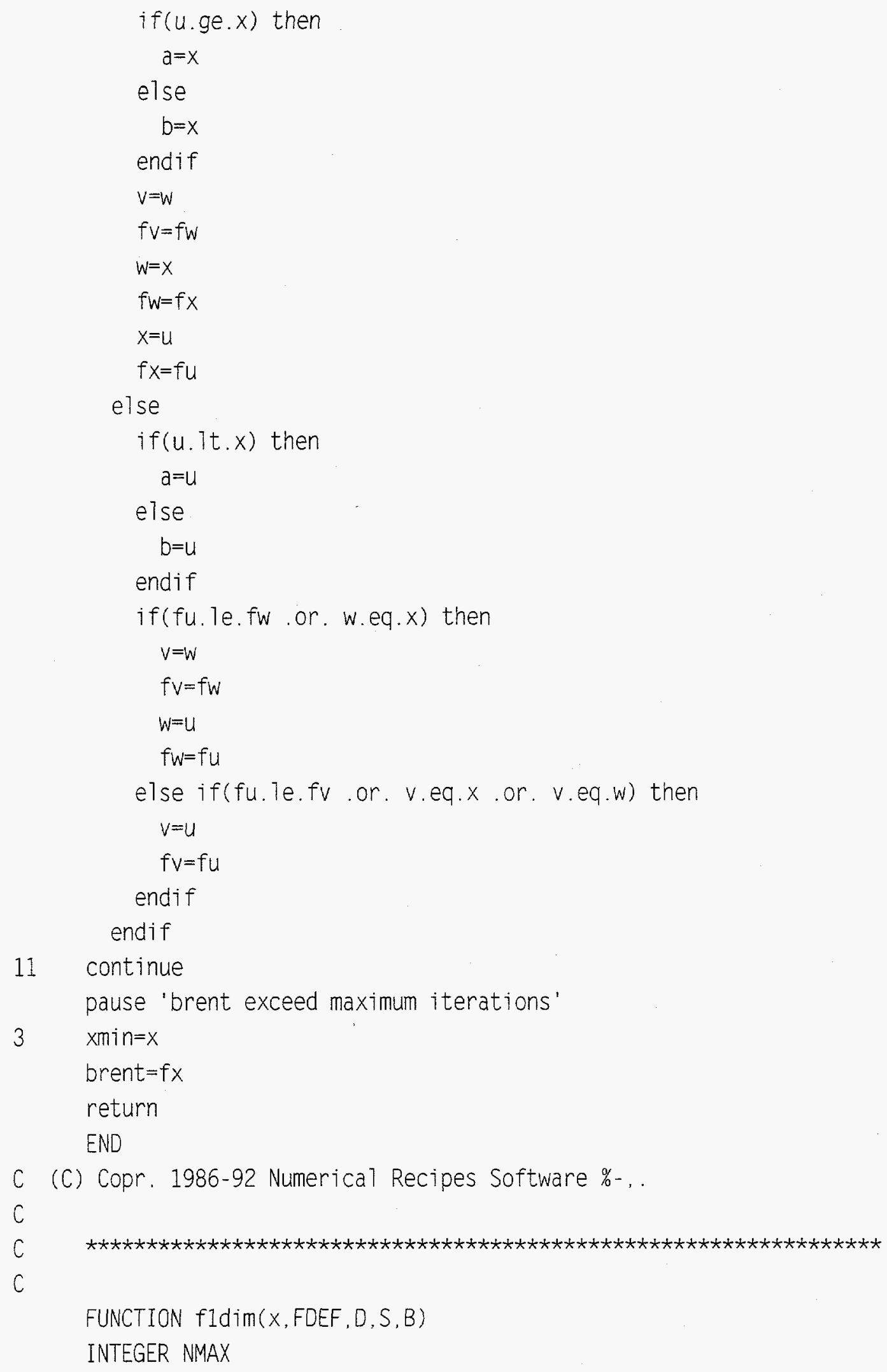


REAL f1dim, func, $X$

PARAMETER $($ NMAX $=500)$

CU USES fUnC

INTEGER $j$, ncom

REAL pcom(NMAX), xicom(NMAX), xt (NMAX)

REAL FDEF $(*), D(*), S(*), B(*)$

COMMON/ficom/ pcom, xicom, ncom

do $11 j=1$, ncom

$$
x t(j)=\operatorname{pcom}(j)+x^{*} x i \operatorname{com}(j)
$$

11 continue

fldim=func $(x t, F D E F, D, S, B)$

return

END

C (C) Copr. 1986-92 Numerical Recipes Software \%-, .

c

C

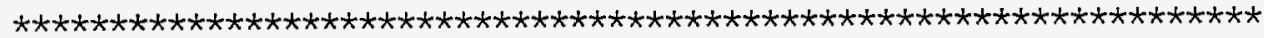

SUBROUTINE RESPONSE ( $B, A, X, Y$, DETNUM. PE, UNITS, NSD, PPMCF)

C

C Calculates the instrument response ("blur") matrix $B$.

C DETNUM is the detector number.

C PE is an INTEGER, the photon energy in KeV.

C

INTEGER I, II,K,L

INTEGER M,NX,NY, NXY, MNXY, IQ

INTEGER DETNUM, PE, NSD

REAL AA, RR, XK, XL, R, ASR

REAL NOP, GPD, TH, ANGC, RHO , AS, PHIOA, ANG2, ANG3

REAL A, PPMCF

PARAMETER $(\mathrm{J}=4)$

INTEGER DET(J)

REAL B(MNXY),X(M),Y(M)

CHARACTER UNITS* 10

COMMON/MN/M, NX, NY, MNXY, NXY

DATA DET/75230, 2670,30860, 1030/

$\mathrm{RHO}=1.6$

$I I=0$ 
PPMCF $=-1.0$

C

IF (DETNUM .EQ. DET(1)) THEN

IF (PE .EQ. 60) THEN

$$
\begin{aligned}
& A A=2.131 E-04 \\
& N O P=2152.15 \\
& \text { GPD }=0.0383 \\
& A S=3.968 E-01 \\
& \text { ANG2 }=1.625 E-02 \\
& \text { ANG3 }=-1.513 E-04 \\
& I I=1
\end{aligned}
$$

ELSE IF (PE .EQ. 583) THEN

$A A=0.979775 E-04$

NOP $=893.60$

$\mathrm{GPD}=0.858$

$A S=0.131596$

$A N G 2=0.0$

$\mathrm{ANG3}=0.0$

II $=1$

ELSE IF (PE .EQ. 911) THEN

$A A=0.799150 E-04$

NOP $=680.88$

$\mathrm{GPD}=0.29$

AS $=0.106931$

ANG2 $=0.0$

ANG3 $=0.0$

$I I=1$

ELSE IF (PE .EQ. 967) THEN

$A A=0.776824 E-04$

$\mathrm{NOP}=656.71$

$\mathrm{GPD}=0.2295$

$A S=0.1038$

ANG2 $=0.0$

ANG3 $=0.0$

$I I=1$

ELSE IF (PE .EQ. 1000) THEN

$A A=7.645 E-05$

$\mathrm{NOP}=642.66$

$\mathrm{GPD}=0.00845$ 


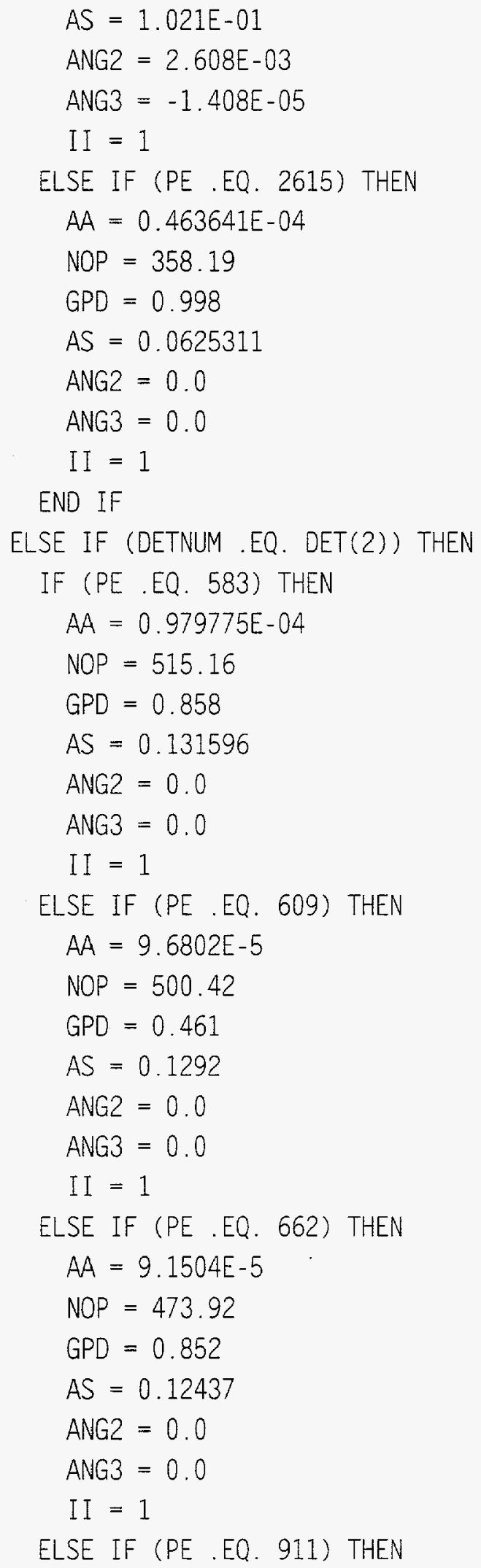




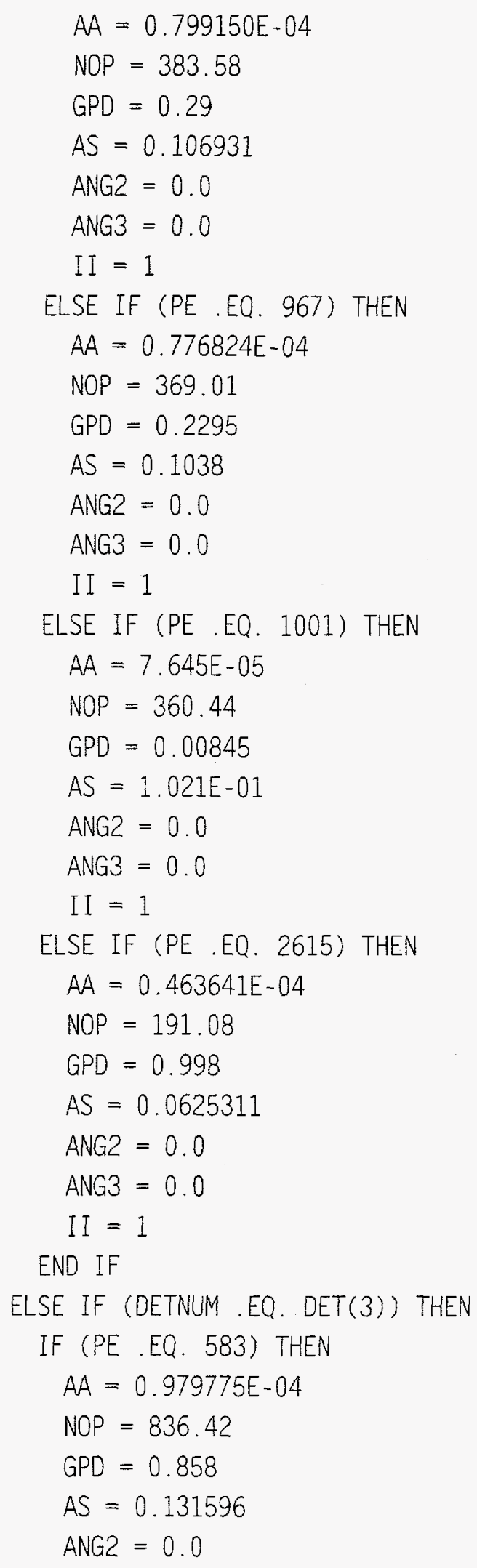




$$
\begin{aligned}
& \text { ANG3 }=0.0 \\
& I I=1 \\
& \text { ELSE IF (PE .EQ. 609) THEN } \\
& A A=9.68025-5 \\
& \text { NOP }=811.86 \\
& \mathrm{GPD}=0.461 \\
& \mathrm{AS}=0.1292 \\
& \text { ANG2 }=0.0 \\
& \mathrm{ANG3}=0.0 \\
& I I=1 \\
& \text { ELSE IF (PE .EQ. 911) THEN } \\
& A A=0.799150 E-04 \\
& \mathrm{NOP}=620.93 \\
& \mathrm{GPD}=0.29 \\
& \mathrm{AS}=0.106931 \\
& \mathrm{ANG2}=0.0 \\
& \text { ANG3 }=0.0 \\
& I I=1 \\
& \text { ELSE IF (PE .EQ. 967) THEN } \\
& A A=0.776824 E-04 \\
& \mathrm{NOP}=597.57 \\
& \mathrm{GPD}=0.2295 \\
& \mathrm{AS}=0.1038 \\
& \text { ANG2 }=0.0 \\
& \text { ANG3 }=0.0 \\
& I I=1 \\
& \text { ELSE IF (PE .EQ. 1001) THEN } \\
& A A=7.645 E-05 \\
& \mathrm{NOP}=584.57 \\
& \mathrm{GPD}=0.00845 \\
& A S=1.021 E-01 \\
& A N G 2=0.0 \\
& \text { ANG3 }=0.0 \\
& I I=1 \\
& \text { ELSE IF (PE .EQ. 2615) THEN } \\
& A A=0.463641 E-04 \\
& \text { NOP }=312.17 \\
& \mathrm{GPD}=0.998 \\
& A S=0.0625311
\end{aligned}
$$




$$
\begin{aligned}
& \text { ANG2 }=0.0 \\
& \text { ANG3 }=0.0 \\
& I I=1
\end{aligned}
$$

END IF

ELSE IF (DETNUM .EQ. DET(4)) THEN

$$
\text { IF (PE .EQ. 662) THEN }
$$

$$
A A=9.1504 E-5
$$

$\mathrm{NOP}=234.35$

$\mathrm{GPD}=0.852$

$\mathrm{AS}=0.12437$

$\mathrm{ANG2}=0.0$

ANG3 $=0.0$

$I I=1$

END IF

\section{ELSE}

PRINT* , ' '

PRINT*,' THE NUMBER OF THE DETECTOR DOES NOT MATCH ANY OF THE '

PRINT*,' DETECTOR NUMBERS LISTED IN THE SUBROUTINE RESPONSE. '

PRINT*, '

PRINT*.' PLEASE CHECK YOUR INPUT FILE. '

STOP

END IF

C

IF (II .EQ. 0) THEN

PRINT* , ' '

PRINT*.' THE PHOTON ENERGY DOES NOT MATCH ANY OF THE ENERGIES'

PRINT*,' LISTED FOR THIS DETECTOR IN THE SUBROUTINE RESPONSE. '

PRINT*, '

PRINT*,' PLEASE CHECK YOUR INPUT FILE.

STOP

END IF

C

IF (NSD .EQ. 1) THEN

PRINT*,' CALCULATING RESPONSE MATRIX / UNIFORM DISTRIBUTION'

PRINT* ', '

PRINT*,' ENTER YOUR CHOICE OF UNITS FOR THE SPECIFIC ACTIVITY,'

PRINT*,' O FOR Bq/g

PRINT*, ' 1 FOR $\mathrm{pCI} / \mathrm{g}$

PRINT*,' 2 FOR ppm : 
$R E A D^{\star}, I Q$

UNITS $={ }^{\prime} \mathrm{Bq} / \mathrm{g}^{\prime}$

IF (IO .EQ. 1) THEN

UNITS $=' \mathrm{pCi} / \mathrm{g}$ '

NOP $=N O P / 27.03$

ELSE IF (IQ .EQ. 2) THEN

PRINT*,' ENTER CONVERSION FACTOR (FROM pCi/g TO ppm) FOR THE' PRINT*, ' RADIONUCLIDE BEING MEASURED

READ*,PPMCF

UNITS $={ }^{\prime} \mathrm{ppm}^{\prime}$

NOP $=($ NOP/27.03)/PPMCF

END IF

C

DO $15 \mathrm{I}=1, \mathrm{M}$

DO $10 K=1, N X$

DO $5 \mathrm{~L}=1, N Y$

$X K=A^{*}(F L O A T(K))$

$X L=A^{*}(F L O A T(L))$

$R R=((X(I)-X K) * * 2)+((Y(I)-X L) * \star 2)+10000.0$

$R=\operatorname{SQRT}(R R)$

$A S R=A S * R$

$T H=57.30 * A \operatorname{COS}(100.0 / R)$

$A N G C=1.0+A N G 2 * T H+A N G 3 *(T H * * 2)$

PHIOA $=(A * * 2) * R H O *(100.0 / R) / 12.566$

IF (ASR .GT. 10.0) THEN

PHIOA $=\operatorname{PHIOA} *(1.0 / R) *(E X P Z E 2 Z(A S R))$

ELSE

PHIOA $=\operatorname{PHIOA} *(E X P(A S R) / R) *(\operatorname{EXPINT}(2, A S R))$

END IF

$B(N X Y *(I-1)+N Y *(K-1)+L)=E X P(-A A * R) * P H I O A * N O P * G P D * A N G C$

5

10 CONTINUE

CONTINUE

15 CONTINUE

ELSE IF (NSD .EQ. 2) THEN

PRINT*, ' CALCULATING RESPONSE MATRIX - PLANE DISTRIBUTION'

PRINT*, '

PRINT*,' ENTER YOUR CHOICE OF UNITS FOR THE SPECIFIC ACTIVITY, '

PRINT* , O FOR Bq/m**2

PRINT*,' 1 FOR $\mathrm{pCi} / \mathrm{m}^{\star \star 2}$ :' 


$$
\begin{aligned}
& \text { READ*, IQ } \\
& \text { UNITS }=' B q / \mathrm{m}^{* * 2} \cdot \\
& \text { IF (IQ. EQ. 1) THEN } \\
& \text { UNITS }=' p C i / \mathrm{m}^{* * 2} \text { ' } \\
& \text { NOP }=\mathrm{NOP} / 27.03 \\
& \text { END IF }
\end{aligned}
$$

C

$$
\begin{aligned}
& \text { D0 } 35 I=1, M \\
& \text { DO } 30 \quad K=1, N X \\
& \text { DO } 25 L=1, N Y \\
& X K=A^{*}(F L O A T(K)) \\
& X L=A^{*}(F L O A T(L)) \\
& R R=((X(I)-X K) * * 2)+((Y(I)-X L) * * 2)+10000.0 \\
& R=S Q R T(R R) \\
& T H=57.30 * A C O S(100.0 / R) \\
& A N G C=1.0+A N G 2^{*} T H+A N G 3^{*}(T H * * 2) \\
& P H I O A=((A * * 2) / 10000.0) /\left(12.566^{* R R}\right) \\
& B(N X Y *(I-1)+N Y *(K-1)+L)=E X P\left(-A A^{*} R\right) * P H I O A * N O P * G P D * A N G C
\end{aligned}
$$

PRINT*, ' '

PRINT*,' THE SOURCE DISTRIBUTION ENTERED DOES NOT MATCH ANY' PRINT*.' OF THE DISTRIBUTIONS LISTED FOR THIS DETECTOR'

PRINT*,' IN THE SUBROUTINE RESPONSE.

PRINT*, ' '

STOP

END IF

C

RETURN

END

C

C

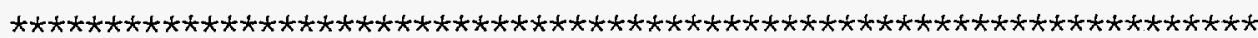

C

FUNCTION expint $(n, x)$

INTEGER $n$, MAXIT

REAL expint, $X$, EPS, FPMIN, EULER

PARAMETER (MAXIT $=100, E P S=1 . e-7, F P M I N=1, e-30, E U L E R=.5772156649)$ 


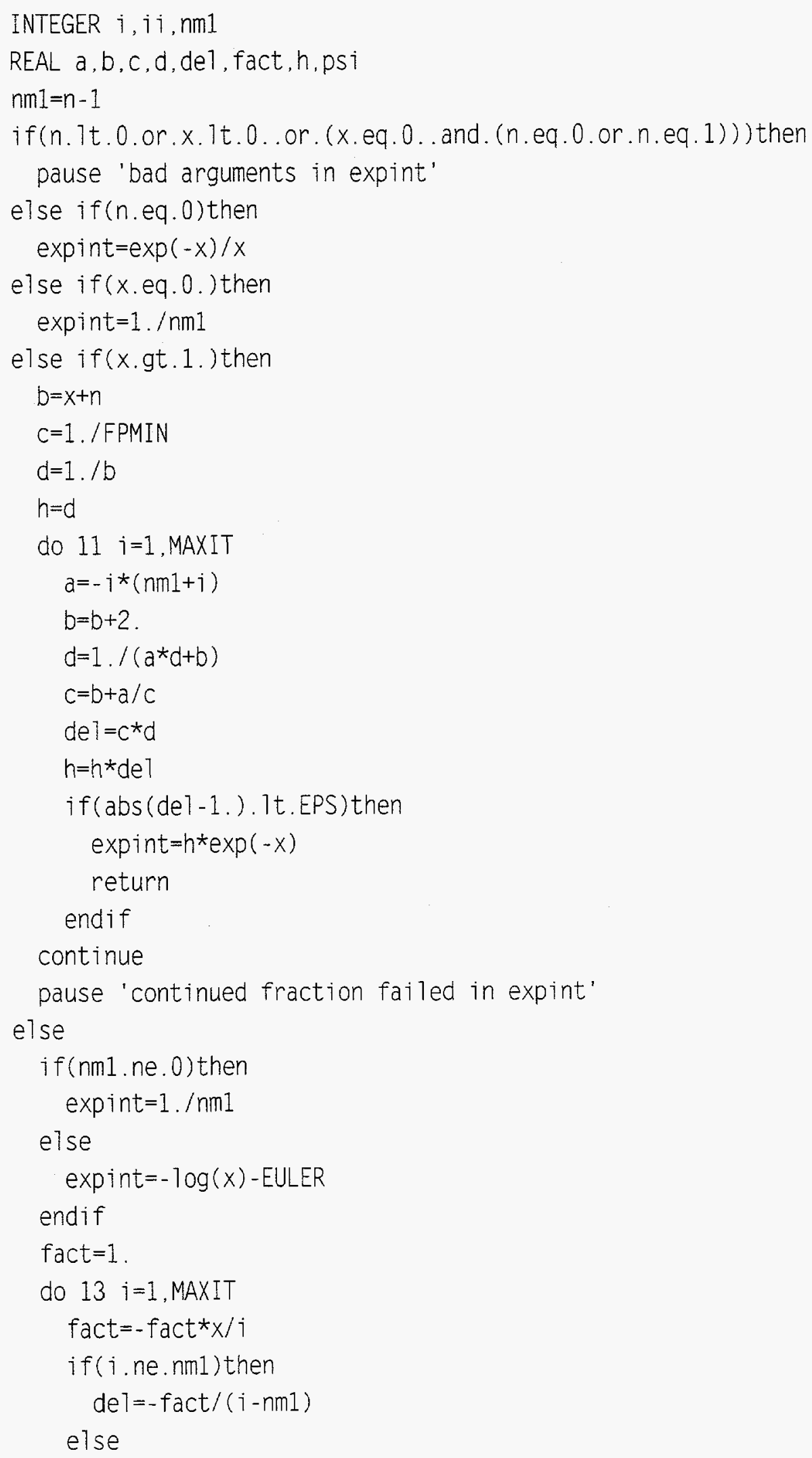




$$
\begin{aligned}
& \text { PS } i=- \text { EULER } \\
& \text { do } 12 \quad i j=1, \mathrm{~nm} 1
\end{aligned}
$$

$$
\text { psi=psi+1./ii }
$$

continue

$$
\operatorname{de} T=f \operatorname{act} *(-\log (x)+p s i)
$$

endif

expint=expint+de 1

if $(\operatorname{abs}(\mathrm{de} 1) .1 t$.abs (expint)*EPS) return

13 continue

pause 'series failed in expint'

endif

return

END

C (C) Copr. 1986-92 Numerical Recipes Software \%-,.

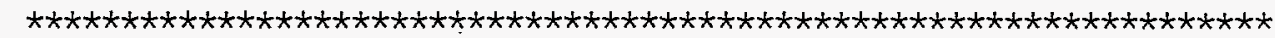

FUNCTION EXPZEZZ(X)

C

C

C

Function to calculate $\exp (x) * E 2(x)$, where $E 2(x)$ is an exponential integral. Uses the rational approximation by Paul Verbeeck.

C "Rational approximations for exponential integrals $E n(x)$ ", in

C Bulletin de l'Academie royale de Belgique (Classe de Sciences),

C page 1064, 5e Serie - Tome LVI, 1970.

C

C $\exp (x) \star E 2(x)=(1 / x) *(v 1(z) / v 2(z))$ where $v 1, v 2$ are third order

$C$ polynomials, $z=1 / x, x>1$, and stated maximum error $<9 . E-06$.

$\mathrm{C}$

REAL $X, A 2, A 3, B 2, B 3$

$\mathrm{C}$
$A 2=2.6731571$
$A 3=0.1212641$
$B 2=4.6660820$
$B 3=3.7340708$

C

EXPZE2Z $=(1.0+(A 2 / X)+(A 3 /(X * * 2))) /(X *(1.0+(B 2 / X)+(B 3 /(X * * 2))))$

C

RETURN

END

C

C

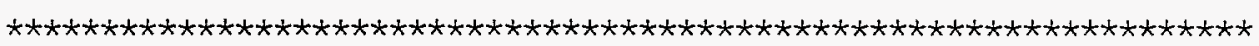

